Positive airway pressure and electrical stimulation methods for obstructive sleep apnea treatment: a patent review (2005-2014)

Daniel Álvarez ${ }^{1}$, Gonzalo C. Gutiérrez-Tobal ${ }^{1}$, Félix del Campo ${ }^{2,3}$, and Roberto Hornero $^{1}$

${ }^{1}$ Biomedial Engineering Group, E.T.S.I. Telecomunicación, Universidad de Valladolid, Paseo de Belén 15, 47011, Spain.

${ }^{2}$ Pneumology Service, Hospital Universitario Río Hortega de Valladolid, c/ Dulzaina 2, 47013, Valladolid, Spain.

${ }^{3}$ Medicine, Dermatology and Toxicology Department, Facultad de Medicina, Universidad de Valladolid, c/ Ramón y Cajal 7, 47005, Valladolid, Spain

Corresponding author: $\quad$ Roberto Hornero

E.T.S.I. de Telecomunicación

Universidad de Valladolid

Paseo de Belén 15

47011 - Valladolid (España)

Phone: +34 983185570

Fax: +34 983423667

E-mail: robhor@tel.uva.es 


\title{
Positive airway pressure and electrical stimulation methods for obstructive sleep apnea treatment: a patent review (2005-2014)
}

\begin{abstract}
Introduction. Obstructive sleep apnea-hypopnea syndrome (OSAHS) is a major health problem with significant negative effects on the health and quality of life. Continuous positive airway pressure (CPAP) is currently the primary treatment option and it is considered the most effective therapy for OSAHS. Nevertheless, comfort issues due to improper fit to patient's changing needs and breathing gas leakage limit the patient's adherence to treatment.

Areas covered. The present patent review describes recent innovations in the treatment of OSAHS related to optimization of the positive pressure delivered to the patient, methods and systems for continuous self-adjusting pressure during inspiration and expiration phases, and techniques for electrical stimulation of nerves and muscles responsible for the airway patency. Expert opinion. In the last years, CPAP-related inventions have mainly focused on obtaining an optimal self-adjusting pressure according to patient's needs. Despite intensive research carried out, treatment compliance is still a major issue. Hypoglossal electrical nerve stimulation could be an effective secondary treatment option when CPAP primary therapy fails. Several patents have been granted focused on selective stimulation techniques and parameter optimization of the stimulating pulse waveform. Nevertheless, there remain important issues to address, like effectiveness and adverse events due to improper stimulation.
\end{abstract}

\section{Article highlights}

i) Limitations of current therapies support the need for novel alternatives in the context of obstructive sleep apnea-hypopnea syndrome treatment. 
ii) A great amount of patents focus on automated adjustment of the delivered breathing gas pressure in continuous positive airway pressure devices, which are the primary treatment option.

iii) A novel approach based on electrical stimulation of the hypoglossal nerve currently focuses the attention of the medical and scientific communities, as shown by the number of patents granted on recent years.

iv) Implanted neurostimulators avoid common limitations of positive pressure-based devices (uncomfortable masks, gas leakage) and surgical procedures (highly invasive, non-reversible) becoming a promising treatment option for obstructive sleep apnea-hypopnea syndrome patients who refuse positive airway pressure-based therapies.

Keywords: airflow limitation, continuous positive airway pressure, electrical nerve stimulation, hypoglossal nerve, obstructive respiratory event, obstructive sleep apneahypopnea syndrome

\section{Introduction}

The obstructive sleep apnea-hypopnea syndrome (OSAHS) is a breathing disorder characterized by temporary but recurrent complete occlusions (apneas) or partial collapses (hypopneas) of the upper airway during sleep. These respiratory events lead to deep oxygen desaturations, blood pressure and heart rate acute changes, increased sympathetic activity and cortical arousals, which prevent patients from resting while sleeping [1,2]. The prevalence of OSAHS is notably higher in men than in women (2-4:1 ratio in community based studies) and it increases with age, body mass index, neck circumference, and waist-to-hip ratio [1-3]. Skeletal and/or soft tissues abnormalities in craniofacial and upper airway structure play an important role in the occurrence of the disease. In addition, some studies support a genetic 
predisposition to OSAHS $[4,5]$. Regarding related comorbidities, high-risk patients include those with congestive heart failure, atrial fibrillation, treatment refractory hypertension, type 2 diabetes, stroke, nocturnal dysrhythmias, and pulmonary hypertension [6].

OSAHS has become a major health problem due to its high prevalence and severe negative effects on health and quality of life $[1,2,7]$. Both adults and children can suffer from OSAHS. Nevertheless, the conditions leading to airway obstruction, its consequences, and the treatment are completely different. OSAHS is linked with the most important causes of death in adults from industrialized countries. Metabolic deregulation and cardiovascular and cerebrovascular diseases, such as atrial fibrillation, stroke, myocardial infarction and sudden cardiac death, could affect people having untreated OSAHS [1, 2, 8]. Furthermore, people's daytime performance is severely affected and hypersomnolence due to OSAHS has been linked with a higher probability for motor-vehicle collisions and occupational accidents [9, 10]. Regarding children, untreated OSAHS leads to several negative consequences in the health and development of infants, such as growth impairment, neuropsychological and cognitive deficits, and/or even cardiovascular dysfunction [11].

Common epidemiological data reflects a high OSAHS prevalence in adults from western countries: 1 to $5 \%$ of adult men and $2 \%$ of women. However, recent studies suggest that $20 \%$ of adults could have at least mild OSAHS and 7\% of adults moderate-to-severe OSAHS [2]. Similarly, the American Academy o Pediatrics recently reported that the prevalence of OSAHS in children is in the range of $1 \%$ to $5 \%$ [11]. Life-threatening consequences have augmented the interest of the general population on OSAHS, exponentially increasing the number of patients for evaluation [12]. Nevertheless, OSAHS is still considered a highly underdiagnosed and undertreated disease. Unlike its high prevalence and negative influence in the quality of life, it is estimated that $90 \%$ of cases in men and $98 \%$ of cases in women may be undiagnosed for many years [8]. Critical points in the management of OSAHS are both diagnostic 
methodology and treatment compliance. Diagnosis starts with an initial subjective evaluation of the sleep history, which highly depends on the symptoms reported by the patient. Next, according to the risk for OSAHS determined by the physician, overnight attended in-laboratory polysomnography (PSG) or portable monitoring (PM) at home is prescribed $[6,13]$. In-lab PSG has been the standard method for OSASH diagnosis. During PSG, the patient's sleep is monitored by means of several sensors during at least one whole night in hospital facilities. The analysis and subsequent interpretation of the results is complex and time consuming, leading to large waiting list $[3,14,15]$. Currently, portable home sleep monitoring has emerged as an alternative for OSAHS diagnosis [3]. According to the AASM rules, PM may be used in patients with a high pre-test probability of moderate-to-severe OSAHS and with no other major comorbid condition or sleep disorder $[6,13,15]$. On the other hand, regarding OSAHS treatment, there are different approaches, including non-invasive therapies such us positive airway pressure (PAP) devices aimed at maintaining the patency of the upper airway, or invasive and irreversible surgical operations that alter the patient's anatomy, such as maxillomandibular advancement, hyoid suspension or uvulopalatopharyngoplasty [3, 6]. Continuous positive airway pressure (CPAP) is the gold standard treatment for OSAHS [16]. According to the recommendations of the AASM, CPAP is indicated for the treatment of moderate-to-severe patients [6]. Individual titration of the pressure level for each patient is needed. The standard procedure is based on the determination of the continuous pressure that normalizes the patient's sleep and breathing during in-lab PSG [17]. However, CPAP titration at patient's home is a widespread alternative procedure due to large waiting lists in many sleep labs [18]. OSAHS is a chronic disease hence long-term treatment is needed. Existing therapies, however, are not consistently effective for all patients and user's acceptance and therapy compliance is below desired levels $[6,19,20]$. 
The present review focuses on recent patents related to OSAHS treatment granted in the last ten years (from 2005 to 2014). Firstly, inventions aimed at minimizing limitations of continuous positive airway pressure (CPAP), which is currently the primary treatment option for OSAHS, are analyzed. Finally, patents linked with electrical nerve stimulation of the hypoglossal nerve, which have shown an increasing interest as a reliable alternative to CPAP, are also discussed.

\section{Obstructive sleep apnea-hypopnea syndrome (OSAHS)}

\subsection{OSAS diagnosis}

Diagnostic criteria for OSAHS are based on clinical signs and symptoms determined during (i) an initial sleep evaluation including sleep oriented history and physical examination and (ii) further comprehensive objective testing by means of in-laboratory full-night PSG [6]. Common topics in the patient's sleep history should include evaluation of snoring, witnessed apneas, choking episodes, excessive daytime sleepiness, total sleep amount, nocturia, morning headaches, sleep fragmentation, and decreased concentration and memory. High-risk patients with nocturnal symptoms should undergo overnight PSG. For the remaining patients, the timing of further sleep testing is determined by the presence of daytime symptoms or comorbidities [6].

During standard PSG, neurophysiological and cardiorespiratory signals are recorded to subsequently analyze sleep and breathing. Thus, electroencephalogram (EEG), electrooculogram (EOG), chin and leg electromyogram (EMG), electrocardiogram (ECG), airflow (AF) by means of thermistor and nasal prong pressure transducer, oximetry, body position, snoring sounds, and video are commonly recorded during the whole night. Every sleep study should be analyzed and interpreted by a qualified physician. The American Academy of Sleep Medicine (AASM) Manual for the Scoring of Sleep and Associated Events define practice parameters, technical specifications, and event scoring rules aimed at minimizing inter- 
scorer variability and improving the quality of the diagnosis [6]. Apnea is defined as a significant reduction (>90\%) of airflow for more than $10 \mathrm{~s}$, whereas hypopnea is defined as a decrease in respiratory flow of at least $50 \%$ (or alternatively $30 \%$ ), accompanied by a desaturation greater than or equal to 3\% (alternatively 4\%) and/or an EEG arousal. The apneahypopnea index (AHI), which is the average number of apnea and hypopnea events per hour of sleep, is the standard index used to diagnose OSAHS and establish its severity [21]. A positive diagnosis is confirmed if $\mathrm{AHI} \geq 15$ or if $\mathrm{AHI} \geq 5 \mathrm{e} / \mathrm{h}$ in a patient reporting any of the following symptoms: daytime sleepiness, un-refreshing sleep, fatigue, insomnia, waking up breath holding, gasping, or choking, or the bed partner describing loud snoring breathing interruptions or both during the patient's sleep [22]. Usually, OSAHS severity is defined as mild $(5 \leq \mathrm{AHI} \leq 15)$, moderate $(15 \leq \mathrm{AHI} \leq 30)$, and severe $(\mathrm{AHI}>30)$ [6]. A split-night study, which consists on an initial standard PSG followed by CPAP titration on the same night if an AHI $\geq$ $40 \mathrm{e} / \mathrm{h}$ is scored during 2 hours, is an alternative [23].

On the other hand, complete PSG is considered labor-intensive, expensive and time-consuming [24], leading to increased waiting lists and delayed access to diagnosis and treatment [14]. Thus, there is a great demand on new techniques aimed at simplifying the standard procedure and/or reducing the number of PSGs needed (screening tests) [25]. The main alternatives to PSG focus on portable monitoring $[24,26]$. Portable monitors are usually classified as type 1 or standard PSG; type 2, which include sleep staging and respiratory measures; type 3, which use at least three respiratory channels; and type 4, which use at least one respiratory channel, usually oxygen saturation or airflow [24]. In addition, automated signal processing techniques have been widely applied during the last years to improve the diagnostic ability of single-channel cardiorespiratory recordings. In this regard, single-lead ECG [27, 28], single-channel AF [29, $30,31]$ and blood oxygen saturation $\left(\mathrm{SpO}_{2}\right)$ from nocturnal pulse oximetry $[25,32,33]$ have been predominantly studied. In order to standardize portable monitoring assessment and help 
physicians to uniformly classify and properly evaluate sleep testing devices, different studies have been carried out during the last years [24, 26, 34].

\subsection{OSAHS treatment}

Surgical (nasal, oropharyngeal and hypopharyngeal procedures, maxillomandibular advancement, and hyoid suspension), medical (CPAP, custom-made oral appliances), behavioral (weight loss, positional therapy), and pharmacological (supplemental oxygen, modafinil) approaches are currently the main alternatives for OSAHS treatment $[3,6,20,35$, 36]. Table 1 summarizes the main alternatives currently available for OSAHS treatment, their advantages and limitations.

CPAP, which was first described by Sullivan in 1981 [37], is considered the standard of care for OSAHS $[6,38]$. Currently, CPAP is the primary preferred treatment of mild, moderate and severe OSAHS. It should be offered as an option to all severe patients or mild to moderate patients showing daytime and/or nocturnal symptoms [6]. There are strong evidences on the effectiveness of CPAP in decreasing symptoms of sleepiness, reducing cardiovascular risk, and improving quality of life in patients suffering from moderate and severe OSAHS [20, 38, 39]. In addition, it has been shown that treatment with CPAP significantly reduces the mortality associated to the disease [40]. On the other hand, although several studies report significant benefits of CPAP treatment for mild patients, several uncertainties still remains [20,38]. During CPAP treatment, the patient sleeps wearing a mask connected to a gas flow generator via a tubing system aimed at delivering a continuous positive pressure of air to keep the airway open [3]. The therapy pressure is constant during the whole night and must be determined during a sleep study (titration) to obtain the optimum value to maintain the airway patency. Though noninvasive, simple and highly effective, CPAP treatment delivers the same constant high pressure both during inspiration and expiration phases, which is unnecessary. Modification of expiratory pressure contour is a technical advance aimed at improving patient's comfort by reducing 
pressure at the beginning of the exhalation. C-Flex (Philips Respironics, Murrysville, PA, USA) and EPR (ResMed, San Diego, CA, USA) are commercial solutions. Nevertheless, there is not scientific evidence that this technical advancement leads to an improvement in adherence or comfort. Side effects of CPAP are air leakage, skin irritation, mouth dryness, nasal discharge and even claustrophobia and panic attacks $[3,19]$. In fact, poor compliance (CPAP usage less than 4 hours per night) ranges from $30 \%$ to $80 \%$ [41] and refusal of treatment is estimated in up to $40-50 \%$ of patients [42].

Bi-level positive airway pressure (BPAP) is an improvement over conventional CPAP therapy. BPAP devices deliver two different pressures: a pressure during patient's inspiration (inspiratory pressure, IPAP) and a lower pressure during expiration (expiratory pressure, EPAP), which fits better with patient's natural needs. Nevertheless, bi-level devices also maintain a constant high pressure during the whole inspiration phase (aimed at overcoming airway obstruction) and a different lower but constant pressure during the whole expiration phase (aimed at decreasing the pressure against which the patient exhales) [3, 43]. Therefore, BPAP therapy suffers from the same limitations than CPAP regarding comfort and treatment compliance. Furthermore, fluctuations and asynchrony between pressure changes (from IPAP to EPAP and vice versa) and patient's respiration can increase patient's discomfort [43]. On the other hand, it has been shown that pressure needed to avoid obstructive events varies during the treatment period due to changes in weight, medication and habits, and even through each single night, depending on sleep stage or body position [43, 44]. Autotitrating or auto-adjusting CPAP (auto-PAP) is an alternative aimed at improving adherence to therapy. Auto-PAP devices optimize the level of continuous pressure through the night, reducing overall mean pressure and minimizing patient's discomfort due to size effects [19]. It is important to emphasize that BPAP and APAP are technical advances with no proven enhancement over conventional CPAP from a clinical point of view. Although these technologies have been shown to be safe and effective, 
no compliance or clinical benefits have been demonstrated [16]. Furthermore, there are several studies reporting there is not significant improvement in comfort, patient's quality of life, treatment adherence and/or a decrease in symptoms when APAP devices are used instead of conventional CPAP [19, 43, 45-50].

Common alternatives to CPAP treatment include oral appliances and surgical procedures, both aimed at correcting anatomic abnormalities which lead to narrowing and obstruction of the upper airway during sleep [51]. Regarding oral appliances, there exist two main approaches [6, 35]: (i) tongue retaining devices, which hold the tongue in a forward position with respect to the resting position, and (ii) mandibular repositioning appliances, which cover the upper and lower teeth and hold the mandible in an advanced position with respect to the resting position. The later is currently the most widely used oral appliance [35]. Although CPAP is the most reliable therapy and should be offered to all patients, oral appliances can be an effective alternative treatment in patients with mild to moderate OSAHS who do not respond to positive pressure delivery and/or life style modification strategies [6]. Oral appliances are the only noninvasive alternative to CPAP that can reach favorable results within a short time. However, this treatment modality is considered still underutilized [35]. Regarding surgical therapy, there are different upper airway reconstructive procedures [6]. In this way, maxillomandibular advancement osteotomy leads to a permanent increase in volume and reduction in length of the upper airway that is correlated with improvement in AHI [52]. Therefore, it could be an effective therapeutic option for severe OSAHS patients who do not respond to primary CPAP or oral appliances [53]. Similarly, surgery can be also considered in mild OSAHS patients who have severe but surgically-correctable obstructing anatomy [6]. However, surgical techniques are highly invasive and irreversible hence there is still a great demand for novel feasible therapies. 
Although oral appliances and surgical procedures are common alternatives in patients who are intolerant to CPAP, they also have important limitations. To overcome these drawbacks, novel non-CPAP therapies have emerged $[52,54]$. The nasal expiratory positive airway pressure (EPAP) (Provent sleep therapy, Ventus Medical Inc., USA) is a unidirectional flow-resistant device aimed at regulating airflow through the nostrils (expiratory flow resistance without any inspiratory resistance). Different studies have been conducted to assess its effectiveness [55, 56]. Significantly $(\mathrm{p}<0.001)$ reduction in AHI compared with initial PSG were reported in mild, moderate and severe OSAHS patients. However, AHI reduction was less than $50 \%$ and severe nocturnal desaturations and persistent nasal blockage were reported, which limit adherence to treatment [54]. A novel oral pressure therapy (OPT) has been also proposed. Winx (Apnicure Inc., USA) is a commercial OPT-based device that applies a vacuum to the oropharynx to pull the soft palate forward and stabilize the tongue in order to maintain airway patency [54]. Colrain et al. assessed the safety and effectiveness of the Winx device in a population composed of mild-to-severe OSAHS patients. Clinically significant improvement in AHI, sleep quality and continuity, and daytime sleepiness were reported [57]. Nevertheless, further work is needed to confirm the effectiveness of such devices as reliable alternative to conventional CPAP therapy. In contrast to the use of physical/technical devices, drug-based treatments have been also proposed for OSAHS. Oral drugs approaches focuses on 5 strategies: increasing ventilatory drive, increasing upper airway tone, decreasing REM sleep, increasing arousal threshold, and increasing the cross-sectional area (or reducing the surface tension) of the upper airway through topical therapy [52]. Although some drug-based therapies may be helpful, additional work is still needed to demonstrate their long-term tolerability and efficacy [52].

Nerve stimulation to control the position of the tongue is a promising alternative. Upper airway dilator muscles play an important role in maintaining upper airway patency during sleep [42]. Different studies suggest that electrical stimulation of the hypoglossal nerve and genioglossus 
muscles using implanted electrodes could lead to significant reductions in upper airway resistance [42]. Moreover, selective stimulation of both the lateral XII nerve branches and the medial nerve branch seems to increase maximum rate of airflow and mechanical stability [42, 58, 59]. Recent studies assessing efficacy of current commercial devices for electrical neurostimulation report significant improvement in AHI and quality of life measures [60-62]. However, PSGs at 6 and 12-month follow up yielded an average decrease in AHI ranging from $53 \%$ to $68 \%$, with a final average AHI varying from 9.0 (4.2 to 22.5 interquartile range) to 19.5 \pm 16.7 (mean \pm standard deviation, SD), suggesting unequal efficacy, especially in obese patients (BMI $\geq 35 \mathrm{~kg} / \mathrm{m}^{2}$ ). On the other hand, limitations of this approach are coarse (nonselective) stimulation of nerves and muscles, fatigue associated to inappropriate stimulation frequency and duration, induced arousals linked with inaccurate stimulation amplitude, inaccurate detection of obstructive events, and asynchronous detection and stimulation modules $[42,63]$. Electrical stimulation of the whole nerve results in combined contractions of both intrinsic and extrinsic muscles, and both retrusor and protrusor muscles, leading to undesirable sensory stimulation and lateral deviation and retrusion of the tongue [63]. Another common issue linked with artificial electrical stimulation of muscles is fatigue due to the stimulating electrode is essentially in a fixed position and the same population of fibers is continuously activated [63]. Although these technical issues have been solved in current available devices, important limitations still remain, such as surgery related complications (transient tongue paralysis), device malfunctions (transient asynchronous stimulation/interruption and electrode breakage) and/or tongue abrasion [54, 60, 61].

In the following sections, recent granted patents (granted from 2005 to 2014) linked with improvements of the standard therapy for OSAHS (CPAP) and the novel electrical nerve stimulation are described. Table 2 summarizes reviewed patents. Firstly, inventions related to PAP therapy are analyzed. Patents are presented according to the approach or kind of device 
proposed by the inventors: auto-adjusting PAPs, bi-level PAPs, and novel devices. Secondly, patents linked with electrical nerve stimulation are analyzed. Inventions are grouped by type of stimulation: continuous vs. event triggered. Finally, a methodology for assessing electrical nerve stimulation-based therapy success before surgery is analyzed.

\section{Positive airway pressure devices}

Determining the minimum pressure that fits the patient's needs has been a major goal of research regarding CPAP treatment. It has been shown that this minimal pressure varies along time according to different variables: sleep stage, body position, weight, medication, and/or patient's habits $[43,44]$. In this regard, Rapoport et al. have been granted a set of patents in Australia [64], Europe [65, 66], Canada [67], and USA aimed at automatically detecting airflow limitation and computing the optimal pressure for the user [68-72]. In [70], airflow limitation is detected by computing four shape-based parameters derived from the present and the preceding breaths: sinusoidal index, flatness index, respiratory effort index and relative flow magnitude index. All these shape-derived parameters are combined (e.g. by logistic regression) to obtain a single measure showing the probability that the current breath has a shape characteristic of flow limitation. Finally, prior probability measures from preceding breaths modify the weight of the current flow limitation index. The proposed self-adjusting system can be used either with a positive pressure device or just for determining the frequency and severity of flow limitations. Similarly, a system aimed at detecting airflow limitations is described in [71]. The main novelty of this invention is the application of a pre-trained artificial neural network to classify individual patient's breaths into the following classes: flow limitation is (i) present, (ii) probably present, (iii) not probably present, and (iv) not present. Flow and/or pressure signals including a plurality of patient's breaths are segmented and parameterized to feed the neural network. In [72], a system, method and apparatus for OSAHS treatment are 
described, aimed at minimizing the airflow pressure while still avoiding flow limitation. The proposed system increases or decreases the airflow pressure in response to inspiratory airflow changes, such as significant deviation from a sinusoid, flattering or the presence of plateaus. According to the inventors, a time weighted majority function is applied to the flow limitation parameter values for a certain number of previous breaths and an automated decision tree is used to decide whether to change the positive controlled pressure taking into account flow limitation indexes of the current and the preceding breaths and previous decisions of the system.

Eklund et al. [73] have been granted a patent for the detection and treatment of disordered breathing during sleep based on artificial neural networks. The invention automatically adjusts the delivered pressure based on the presence of respiratory events. According to the inventors, the flow or pressure signal in the CPAP circuit is continuously monitored using a constant sampling frequency. This signal is periodically parameterized by computing respiration-related variables (cepstrum coefficients and the energy trend parameter), which are fed to the artificial neural network (Kohonen's self-organizing maps) in order to recognize patterns characteristic of airflow limitation. Sleep disordered breathing is determined if the number of outputs of the network during a selected interval exceeds a preselected threshold value. Accordingly, the amount of breathing gas provided to the patient is increased until a normal breathing pattern is re-established.

Similarly, Waxman et al. have been recently granted a patent for the detection and prediction of physiological events in people suffering from sleep disordered breathing [74]. The proposed system pre-processes (segmenting, transforming and encoding stages) physiological input data and feeds a neural network to predict sleep-related breathing events within the next $60 \mathrm{~s}$ in order to control airway pressure levels generated by PAP devices. In preferred embodiment, the Authors propose to use the Wavelet transform in the pre-processing stage and the Large Memory Storage and Retrieval (LAMSTAR) neural network in the pattern recognition stage. 
Similarly, in [75], the Authors describe a learning control system based on one or a plurality of artificial neural networks aimed at controlling the breathing support for increasing effectiveness of PAP-based therapies.

The use of signal processing techniques is a common feature of this group of patents. They apply different pattern recognition methodologies (logistic regression, neural networks and decision trees) to detect respiratory events and regulate the pressure level while allowing estimating the AHI during the treatment. This technology has been incorporated by different CPAP manufactures, such as Philips Respironics, ResMed, Fisher \& Paykel or Breas, enabling clinician follow-up and CPAP effectiveness assessment. However, further studies are needed to evaluate whether this information can improve CPAP adherence.

Detecting when the patient is asleep or awake is a novel promising approach for increasing patient's comfort [76, 77]. In this regard, Rapoport et al. have been granted a patent for adjusting the positive airway pressure supplied to a patient [78]. The patient's breathing patterns are analyzed by a signal processing algorithm in order to detect the following patient's states: (i) regular breathing, (ii) sleep disordered breathing, (iii) REM sleep, and (iv) troubled wakefulness. The signal processing system monitors airflow and pressure signals from conventional flow sensors coupled to the PAP device. If pure mouth breathing, erratic large breaths with varying inspiratory times, or irregularity of intervals within breaths (but not cyclic apneas) are detected, then the system determines whether the patient is awake and anxious or distressed (troubled wakefulness). Then, the pressure applied by the PAP device can be lowered, which should improve the user's comfort until the patient falls asleep. Resumption of regularity or detection of cyclical and regular respiratory events characterizes breathing patterns when a patient is asleep. In [79], the invention by Rapoport et al. describes a therapeutic pressure mode when the system determines that the patient is asleep while a sub-therapeutic pressure mode is applied when the system determines that the user is awake. Similarly, in the 
invention described by Nightingale et al. [80], the proposed system provides a sub-therapeutic pressure level at the beginning of the treatment session or when wakefulness is detected while operating in a therapeutic delivery mode when the patient is asleep. The system determines if the patient falls asleep by comparing the elapsed time since the last conscious user interaction with the system (e.g. activating a button from the user's interface) or since the device was turned on with a threshold. This value may be fixed (averaged user sleep patterns), settable (by the user or the physician) or adaptive (dependant on current and/or past breathing patterns). In both patent applications $[79,80]$ the Authors suggest to use the methodology proposed in [78] to decide whether the patient is awake or asleep. Leading CPAP manufactures, such as ResMed and Fisher \& Paykel incorporate this technology into their commercial devices. Although some studies have assessed the effectiveness of these techniques for sleep onset and awakening detection $[76,77]$, further investigation is needed to evaluate their actual long-term influence on patient's comfort and CPAP compliance.

A proportional PAP (PPAP) device has been granted in Australia [81], Canada [82], Europe $[83,84]$ and the USA [85-87]. The main characteristic of the proposed invention is that the breathing gas is delivered to the patient at a minimally sufficient pressure during at least a portion of the breathing cycle to prevent airway collapse. Two operating parameters allow for controlling the delivered pressure: (i) a first gain or inspiration gain, which modifies (multiplies) the current estimated flow rate in order to compute the pressure during inspiration, and (ii) a second gain or expiration gain, which is used during exhalation to reduce the delivered pressure based on the current estimated flow rate. Patent [87] is a continuation of previous patent documents. In this invention, it is described a method and an apparatus for determining whether the patient is experiencing obstructive or central apneas based on the output of a sensor. A comparison between a short-term average of peak inspiratory flow rate or tidal volume (e.g. a 3 breath average) and a long-term average (e.g. greater than 20 breaths) is computed. Once an 
apnea is detected, the system automatically increases the inspiration gain, waits approximately 1 second, and then decreases the pressure back to the original value. If a significant change in the airflow is detected, then the system concludes that the airway is open (central apnea), whereas if there is no significant change, the system concludes that the airway is closed (obstructive apnea).

W.D. Childers \& R.O. Childers $[88,89]$ have been granted a pair of patents linked with the automated setting at-home of a PAP device in order to manage/adapt to patient-to-patient variations and/or changes in particular patient's conditions. The proposed method and apparatus includes 2 different operating modes: standard and custom. The custom operating profile is characterized by customized parameters based on a prescription according to the patient's therapeutic needs, including increased maximum therapeutic pressure, initial pressure and duration prior to an obstructive event and incident pressure and duration during an obstructive event. In addition, operating parameters can be optimized for long term therapy or for transient conditions (e.g. temporary nasal congestion). The inventors suggest the use of a backlit LCD or OLED touch screen as user interface and an USB or wireless RFID link to communicate with the system controller. The main novelty of this invention is the description of the user interface for automated setting of the device at-home according to the changing patient's therapeutic needs. As previously stated, at-home diagnosis and treatment is the focus of physicians and manufactures due to the chronic and variable nature of OSAHS. Therefore, novel devices may incorporate this technology to allow user interactions that could increase patient's comfort and treatment compliance.

Recently, J. Sun $[90,91]$ has been granted a patent for providing bi-level positive pressure to a patient. Sun proposes a novel technique to avoid the delay between the detection of inspiration and expiration stages in the respiratory cycle and the adjustment of the required pressure (IPAP or EPAP). De-synchronization could lead bi-level therapies to fail if the computed pressure at 
the end of the last expiration is lower that the optimal pressure needed to avoid the airway collapse in the present inspiration. An expiratory unloading factor is computed based on the correlation between the inspiratory (expiratory) pressure and the inspiratory (expiratory) motor load generating the flow of air. Two sensors (an airflow pressure sensor and a load sensor) are used to generate the pressure signal and the load signal. The expiratory unloading factor indicates the difference in the motor load required to generate the inspiratory and expiratory pressures at the patient interface.

M. D. Hallet [92] describes a method for providing bi-level automatic respiratory support for treatment of sleep disordered breathing. This invention is aimed at automatically detecting the user's need to initiate lung empting (expiration) in order to provide a lower pressure. In addition, the system is also designed to minimize patient's effort during inspiration to achieve airway stability. Delivered pressure is governed by respiratory-related parameters, such as rate, tidal volume, average minute ventilation, presence of residual inspiratory effort, and based on average quiet, stable breathing levels over the past 2 to 10 minutes (moving average minute monitoring). Upper and lower delivered pressures are adjusted if airway instability or inspiratory flow resistance (flow limitation) are detected.

Although non-fixed pressure devices are becoming more commonly prescribed in some countries [93], regarding the reviewed patent documents, there have been no major changes in BPAP and APAP devices for OSAHS during the last decade. Comfort and effectiveness have improved because PAP-based devices are smaller, integrate humidification, and airway pressure is delivered in novel ways. Technological advances such as the use of multiple sensors, signal processing algorithms and control modules have enabled fine control of the pressure level delivered to the patient. Nevertheless, the operating principle, i.e. deliver a positive pressure to maintain airway patency, is not different than in those manufactured in the last 1020 years. 
A complete enclosure was developed by D. Grady [94] for the treatment of OSAHS, which consists in a base connected to a bed, a canopy connected to the base and a sealing member that connects the canopy to the base, so that both elements form a substantially airtight enclosure around at least a portion of the bed. A conventional CPAP can be connected to generate continuous positive airway pressure within the whole enclosure. The main feature of this invention is that continuous positive pressure is delivered to the patient without the need for a fitted mask, which avoids common compliance issues of conventional treatment. Additional benefits described in the invention are control of humidity and temperature within the pressurized enclosure and attenuation of sound and light in order to facilitate sleep. On the other hand, the proposed invention is far away from the current trend of leading manufactures, which focus on developing smaller and portable devices.

P.J. McAuliffe and D.L. Bullock [95-100] have been granted a set of patents for controlling the pressure and/or flow rate of breathable gases by means of a flow diverter valve during noninvasive positive pressure ventilation therapy. The aim of this invention is to reduce noise and to improve the blower motor response time in order to prevent patient discomfort. To achieve this goal, the inventors describe (i) a flow diverter valve with reduced noise, flow fluctuations and increased response speed, and (ii) a valve assembly with a flow diverter rotatable vane that does not choke a blower regardless of the vane position. The position of the rotatable vane changes according to patient's needs dividing the airflow between an exhaust and an outlet port. The aerodynamic characteristics of the vane (and thus the flow characteristics and the response time) depend on specific parameters, such as the radii of curvature, the distance between centers of the radii of curvature and the leading vane corners, the position of the rotator vane within the device, and the width and length of the flow paths.

Previous reviewed patents focused on different methodologies for controlling the airflow pressure level delivered to the patient during expiration and inspiration. However, an important 
issue concerning the comfort and successfulness of the treatment is linked with the mask, which is in direct contact with the patient. Mask technology focused the attention of manufactures during the last years. In fact, performance of existing respiratory masks is noticeably higher than preceding ones and may be responsible for the improvement in therapy compliance and user's comfort over the past decade. The most important limitation of these masks is the leakage, i.e. undesirable escape of the gas under pressure. This problem is two-fold: in one hand, leakage negatively impacts the treatment efficiency and, on the other hand, it causes important discomfort for the patient. The invention by Luca et al. [101] describes an improved membrane cushion able to provide efficient mask tightness whatever the patient's physiognomy. Fitness to different patient's faces is achieved by using cushion membranes of different thicknesses in different regions of the mask (upper nasal bridge, cheek regions on both sides of the nose and lower chin region under the mouth). Efficient gas tightness and increasing comfort for the patient depends on specific parameters specified by inventors, such as thicknesses of internal and external membranes of the cushion in the different regions and a variable number of cuts in the central portion of the cushion. Similarly, Lithgow et al. [102] have been granted a patent for controlling the distribution of contact force of a respiratory mask around the patient's face. In this invention, uncomfortable high pressure along sensitive regions of the patient's face, e.g. nasal bridge and lip region, is reduced to increase user's comfort while maintaining the cushion seal. This is accomplished by varying the size, shape, geometry and materials of different external and internal structures of the cushion (membranes, rims, gusset areas and outer/inner edges). In [103], Barnett et al. describe a nasal mask with a flexible sealing element including a structural reinforcement area of increased thickness around the perimeter of the cushion. A saddle shaped contoured area is included on each side of the sealing member, each one having upper and lower protrusions for providing supporting contact with the face. In addition, the distal portion of the cushion includes an in-turned lip that is turned toward the 
nose receiving cavity. The degree of roll of the lip controls the contact area of the mask-patient interface and it can be increased or decreased depending on the desired seal and patient's comfort.

\section{Electrical nerve stimulation}

Recurrent airflow cessations characteristic of OSAHS have been linked with a decline in the upper airway neuromuscular activity during sleep [104]. This knowledge has supported the development of several patents related to electrical nerve stimulation of the hypoglossal nerve as a novel treatment for OSAHS. In this regard, Lima \& Craig [105, 106] have been granted two patents for treating OSAHS based on a RFID-enabled microelectronic neurostimulator system. A transponder located in the implant (a passive RFID transponder or an active transponder) allows for the communication with the external subsystem. The inventors suggest that this external subsystem may be shaped for placement around a patient's ear or with a patch placed in the skin. Electrical nerve stimulation depends on patient-specific nerve physiology and parameters that can be set in a controller (frequency, amplitude of the signal, number of electrodes involved in the stimulation, among others). One of the main characteristics of this invention is selective stimulation of both hypoglossus and styloglossus, which results in an increased maximum rate of airflow and mechanical stability of the upper airway. This is done by using a matrix arrangement of electrodes that provides multiple nerve stimulating points: different nerve fascicles can be accessed enabling selective stimulation of a particular area of the nerve. The patent describes different stimulation modes: continuous, i.e. constant stimulation to maintain tongue muscle tone typically during sleep hours, and upon preprogrammed conditions, i.e. under patient-specific intervals, both during sleep hours and while the patient is awake. 
Recent patents by Meadows et al. granted in Australia [107] and USA [63, 108] described a novel methodology for the selective electrical stimulation of the motor efferents of the hypoglossal nerve. To achieve this goal, a programmable electrode is used. It is composed of a plurality of contacts for the selective activation of targeted nerve fibers (motor neuron subgroups) within a nerve bundle and, consequently, their associated motor groups (innervated muscles). According to the inventors, the stimulation is controlled by different parameters, such as stimulation onset, amplitude (gradual ramping from threshold to target amplitude), frequency and duration. In addition, inventors describe a system to minimize fatigue based on the modulation of the amplitude of the stimulating signal, so that stimulation is applied for a certain amount of time and then stopped to let the muscles rest (stimulation duty cycle). Electrical stimulation is applied to different fiber groups using different contacts placed in the fixed stimulating electrode, so that none of the groups is activated long enough to cause significant fatigue. In addition, the frequency of the stimulation is reduced because higher activation frequency leads to higher fatigue. The inventors obtain the desired functional stimulation rate as the sum of the rates of different fiber groups working together (overlapped activation) but activated sequentially (delayed activation). According to the inventors, this activation methodology allows for a continuous or near-continuous (open loop) stimulation of the tongue, so that there is no need to synchronize activation and breathing or to monitor for apneas using additional sensors and signal processing techniques. Therefore, the system complexity decreases, as well as the surgical procedure complexity, power consumption, and the whole cost.

A recent group of patents by McCreery [109-111] described an apparatus, a system and a method for the treatment of OSAHS based on the electrical stimulation of the hypoglossal nerve. The invention comprises a sensor to monitor both the position of the tongue and the force exerted against the sensor and a set of electrodes to deliver electrical stimuli to the ventral 
surface of the tongue. In a normal state, the tongue is extended and contacts the sensor exerting a force against it, whereas during apneic events the airway collapses due to the reduction of the tone of the muscles of the upper airway accompanied by the prolapsed of the tongue base onto the airway. The proposed system detects that the tongue is in a posterior position and delivers a train of electrical stimuli to the branches of the motor nerves innervating muscles that protrude the tongue to move it to an anterior position in order to avoid obstruction of the airway. The proposed sensor comprises an emitter (e.g. LED) and a detector (e.g. phototransistor). The position of the tongue is monitored measuring the intensity of pulsed infrared light from the emitter that is back-scattered from the tongue to the detector.

A group of patents by Bolea et al. [112-116] describe a fully or partially implantable neurostimulator system of the hypoglossal nerve. Claims in patent documents $[112,113,115]$ focus on different electrode configurations, whereas claims from patent [116] mainly focus on signal processing and triggering techniques. In patent document [114], the inventors include additional information about external control devices, physical electrode characteristics and accommodation techniques, methods for detecting sensor failure, alternative nerve stimulation sites (e.g. cranial root of the accessory nerve or superior laryngeal nerve), additional techniques for automated monitoring and processing of respiration in order to trigger stimulation, and new characteristics of the stimulating pulse waveform. In a preferred embodiment, electrical stimulus is triggered as a function of the respiration, which is monitored by the implanted or external respiration sensing leads in a close-loop feedback system. The following signal processing stages are specified to obtain a usable trigger signal for stimulation: amplification, filtering, artifact removal (cardiac and motion artifacts), detection of fiducial points (inspiration and expiration onset derived from the first and second derivative of the respiratory signal), and special events detection (obstructive and central apneas, hypopneas, sleep stages). The following respiratory derived parameters are used: peak-to-peak $(P P)$ magnitude, coefficient of 
variation $(C V)$ of the $P P$ magnitude, maximum and minimum PP amplitudes (PPmax and $P P \min$ ), and $P P$ range. According to the inventors, the stimulus is delivered just from the beginning to the end of the inspiration phase of the respiratory cycle in order to minimize nerve and muscle fatigue. A self-adjusting predictive trigger algorithm based on the estimation of the inspiratory onset from previous respiratory cycles (reference/historical fiducial data) is used, which is specific to a person, sensor location, sleep stage, and sleep position, among other factors. Alternatively, the electrical neurostimulation system may also operate in an open-loop process, where stimulus is derived according to a preprogrammed parameter setting.

In a patent by Tesfayesus et al. [117], a complementary methodology for assessing the likelihood of therapeutic success of electrical stimulation of the hypoglossal nerve for treating OSAHS before the surgery is described. According to the inventors, this stage is necessary because response to hypoglossal nerve stimulation varies across subjects. To achieve this goal, the inventors propose a methodology for observing the patient's upper airway during a tongue protrusion maneuver, which mimics the effect of genioglossus activation by hypoglossal nerve stimulation: the larger the airway size increase during the process, the larger subsequent therapeutic benefit for the patient. The upper airway is observed by endoscopy while the patient is awake and supine.

The Upper Airway Stimulation (UAS) system by Inspire Medical Systems Inc. (Maple Grove, MN, USA) is a fully implanted device for electrical stimulation of the hypoglossal nerve. The Inspire II is the second generation of the UAS system and it has been recently approved by the Food and Drug Administration (FDA) for commercialization in the context of OSAHS treatment. It is important to point out that Inspire Medical Systems is a Medtronic's spin-off, which decided to spin out this technology and its related patents in 2007. In this regard, Inspire Medical Systems is currently the owner of a significant patent portfolio related to electrical nerve stimulation for treating sleep disordered breathing, which has led to the recent FDA 
approval. In addition, novel patents regarding the management of the implantable neurostimulation system [118], a methodology for suitable patient selection for therapy [119], and nerve cuff characteristics [120] have been recently granted. Furthermore, patent applications associated with minimally invasive techniques for insertion of sensing and stimulation leads [121, 122], suitable electrode positioning [123], and a methodology for monitoring the respiratory effort to control the therapy level [124], are currently under review. Regarding the granted patents, Christopherson et al. have been recently granted a system for automatically initiating and adjusting therapeutic treatment of sleep apnea [118]. The patent document focuses on an automatic therapy manager. The invention comprises a sensing module aimed at monitoring respiration and body position (activity and posture sensors), an implantable pulse generator in communication with the sensing module, and an automatic therapy manager for delivering (or stopping) electrical nerve stimulation when sleep disordered breathing (or normal sleep) is detected. The therapy manager is aimed at optimizing treatment (i) by performing variable sampling of physiologic conditions (higher sampling rate during periods of lower patient activity corresponding to higher likelihood of sleep) and (ii) by managing transitions between states of operation according to physiological-based criteria (a severity score based on quantity, duration and intensity of airway obstruction is computed and electrical stimulation is delivered/stopped accordingly). On the other hand, this kind of therapy is more expensive than the standard CPAP-based treatment and invasive surgery is needed to place the implanted neurostimulator. Thus, patient eligibility is an important task to select patients who will really benefit from this therapy in the context of electrical nerve stimulation. In this regard, the invention by Q. Ni [119] describes a methodology for patient screening. Firstly, the method builds an obstruction feature vector composed of the location, pattern, and degree of the obstruction based on the analysis of upper airway images, as well as pressure and airflow recordings during respiration. Then, the system derives a patient candidate profile by applying 
a patient candidate filter to the patient health history, composed of the CPAP compliance history, co-morbidities, BMI, and the AHI. Finally, a patient evaluation module uses the patient candidate information and the obstruction vector to automatically determine patient eligibility for electrical nerve stimulation therapy. Regarding stimulation lead characteristics, the patent by Johnson et al. describes an electrode cuff for easy placement as well as secure and suitable electrical stimulation [120]. The invention illustrates the different modules composing the electrode cuff, their lengths and widths, and the number, disposition, and separation of the electrodes along the stimulation lead in different embodiments. In addition, a method of implanting the detailed electrode cuff is described.

The Nyxoah's neuromodulator (Nyxoah, Mont-Saint-Guibert, Belgium) is an ultra-small system for electrical stimulation of the nerves of the tongue to prevent upper airway collapse. Unlike similar solutions, the implant module is extremely small because it has no internal battery: the energy is supplied by means of an external disposable battery patch. In addition, there are no wires contacting the nerves because stimulation is performed through an electric field, which simplifies the surgery procedure. The Nyxoah's technology is protected by a group of granted patents. Patent documents by Mashiach and Mueller [125] and Mashiach [126] describe a methodology to detect tongue movements based on the degree of coupling (capacitive coupling, radiofrequency coupling, or inductive coupling) between a primary antenna associated with an external processor and a secondary antenna integrated in an implanted unit in contact with the patient's tongue muscle. The external processor determine if a movement is indicative of a precursor to sleep disordered breathing and sends a control signal to the implant in order to cause the contraction of the muscle. The characteristics of the modulation control signal (voltage amplitude, current amplitude, pulse frequency, or pulse duration) are related to the severity of the sleep disordered breathing. One of the main advantages of the Nyxoah's technology is that the implanted unit does not require contact with 
the nerve to achieve effective neurostimulation. Patents by Mashiach [127-129] describe this novelty. The noncontacting stimulation is based on the so called nerve modulation, which uses field-generating electrodes to regulate nerve activity through delivery of energy. The internal unit includes modulation electrodes located in the vicinity of the target nerve (the nerve to be modulated, e.g. next to the subject's tongue in the vicinity of the hypoglossal nerve). These electrodes generate an electric filed in response of a control signal so that a portion of the field lines extend along the length of the nerve. Efficacy of modulation increases when parallel electric field lines run partially or substantially parallel to the nerve fibers to be modulated. The electric field provides energy to the nerve and creates an adequate voltage change to activate the nerve and propagate an electrical signal. Regarding the power source of the battery-less internal unit, the energy is transferred to the implant from the external unit by means of electromagnetic signals, e.g. microwave, infrared, or radio-frequency. A control signal is applied to the primary (external) antenna in order to supply power to the implant. Then, a new signal is induced on the secondary (internal) antenna. This induced signal is transformed using active and/or passive circuit components and supplied to the electrodes for generating the electromagnetic field. Patent documents [129-131] describe the characteristics of the signals used both to activate the implant and to cause muscular contraction.

Recent studies assessed long-term effects of commercial hypoglossal neurostimulator devices $[60,61]$. In the study by Mwenge et al. [60], the AURA6000 ${ }^{\text {TM }}$ (ImThera, San Diego, CA, USA) was implanted on a population of 13 severe OSAHS patients. After a 12-month-long study, 10 patients showed a significant decrease in AHI, microarousal index and ODI. Fatigue due to continuous stimulation was not reported [60]. By contrast, surgery related complications (transient ipsilateral hemitongue paresis) and/or adverse events due to technical malfunction (transient therapy interruption, inappropriate stimulation or even component replacement) were reported [60]. In the study by Strollo et al. [61], clinical safety and effectiveness of the Inspire 
UAS system (Inspire Medical Systems Inc., Maple Grove, MN, USA) was assessed in a population composed of 126 participants with moderate-to-severe OSAHS. Both AHI and ODI4 significantly decreased at the 12-month follow up compared with baseline scores. On the other hand, some adverse events were also reported, which included device repositioning due to serious discomfort (1.6\% patients), temporary tongue weakness (18\% patients), discomfort due to inappropriate stimulation (40\%), tongue soreness and/or abrasion (21\%). Regarding residual effects of hypoglossal neurostimulation therapy after treatment withdrawal, Rodenstein et al. showed a significant clinical residual effect at least during one night, i.e. OSAHS symptoms did not reappear when the treatment stopped [132]. Conversely, CPAP is characterized by limited intranight and night-to-night effect. On the other hand, Woodson et al. reported that apnea events and associated daytime symptoms reappeared after 1-week treatment withdrawal [133]. Similarly, Eastwood et al. [62] recently carried out a multicenter study involving 21 moderate-to-severe OSAHS patients to test the efficiency of the HGNS® neurostimulator system (Roseville, MN, USA). After 3 month-long therapy, the Authors reported a decrease in mean AHI by 56\% (from 43 to 19), with decreases in total and respiratory-related arousals (47\% and 66\%, respectively). Sleepiness, sleep quality and quality of life questionnaire scores also improved [62]. However, 71\% of patients reported at least one adverse event including tongue abrasion. Furthermore, the results suggested that a BMI greater than or equal to $35 \mathrm{~kg} / \mathrm{m}^{2}$ would be an indicator of poor performance.

Appropriate identification of those patients more likely to benefit from electrical nerve stimulation is an important task to optimize therapy success. In this regard, two relevant studies have been carried out in the context of safety and efficacy assessment of the Inspire II UAS system (Inspire Medical Systems Inc., Maple Grove, MN, USA) [134, 135]. In the study by Van de Heyning et al., the device was implanted in a population of moderate to severe OSAHS patients who failed o were intolerant to CPAP. The goal was to derive therapy success 
predictors [134]. Responders met the following criteria: $\mathrm{BMI} \leq 32 \mathrm{~kg} / \mathrm{m}^{2}, 20 \mathrm{e} / \mathrm{h}<\mathrm{AHI} \leq 50$ e/h, and did not show complete concentric collapse (CCC) at the level of soft palate, as determined by drug-induced sleep endoscopy (DISE). The assessment of these predictors as patient selection criteria reported significant reduction $(p$-value $<0.01)$ of AHI from baseline, as well as significant improvement in the Epworth Sleepiness Scale $(p$-value $<0.01)$ and Functional Outcomes of Sleep Questionnaire $(p$-value $=0.02)$ at 6-month postimplant followup. Similarly, in the study by Vanderveken et al., the DISE procedure was assessed as a single tool to predict therapy success before the UAS system implantation [135]. A population composed of 21 patients with moderate to severe OSAHS (AHI $\geq 15 \mathrm{e} / \mathrm{h}$ ) and BMI $<35 \mathrm{~kg} / \mathrm{m}^{2}$ were involved in the study. Treatment success was defined as AHI $<20 \mathrm{e} / \mathrm{h}$ after treatment and AHI reduction $>50 \%$ from baseline. The results showed $81 \%(13 / 16)$ therapy success in the subset of patients without CCC at the level of the palate, whereas no treatment success was reported (0/5) in patients with CCC. Significant reduction of AHI ( $p$-value $<0.001)$ from baseline and significant improvement of EES ( $p$-value $=0.02$ ) were reported.

\section{Conclusion}

OSAHS is a highly prevalent disease that has become a major health problem. Despite its severe consequences to patient's health and quality of life, it is considered underdiagnosed and untreated. CPAP treatment is currently the standard of care for OSAHS. It is considered the most effective method for avoiding obstruction of the upper airway during sleep. However, several long-term trials have evidenced that patient's adherence to therapy is not high enough. In this regard, unnecessary high pressure while the patient is awake, insufficient pressure level during obstructive events and leakage due to poor fitness to patient's physiognomy limit patient's comfort and treatment compliance. In order to overcome these limitations, several patents have been granted in the past few years. Inventions are mainly aimed at automatically 
detecting airflow limitation and computing the optimal pressure for the patient, according to respiratory phases and changing needs during the night (normal vs. disturbance breathing and sleep $v s$. awake). Nevertheless, while non-fix pressure devices incorporating these advances are at present commonly prescribed, several studies have shown no clear evidences whether APAP and BPAP yield to improved compliance, comfort, and nocturnal or daytime symptoms. Therefore, based on current and extensive clinical experience, we can conclude that constant CPAP may be as effective and preferred by patients as proposed PAP-based alternatives. On the other hand, an important effort has been also carried out during the last decade to optimize patient's masks in order to minimize breathing gas leakage, which has led to an actual improvement in patient's comfort. Alternative therapies to CPAP include behavioral, pharmacological, and surgical approaches, as well as custom-made oral appliances. While changes in life style and pharmacologic agents are usually adjunctive therapies aimed at improving AHI, surgery and oral appliances are actual primary or secondary treatment options for OSAHS. Nevertheless, less invasive and non-permanent alternatives are needed. In this regard, stimulation of the hypoglossal nerve by means of implanted electrodes focuses the interest of physicians and researchers. In this context, different patents have been granted, mainly aimed at optimal selective stimulation of nerve and muscles responsible for airway patency and automated triggering of the electrical stimulus. However, surgery related complications and adverse events due to technical malfunction of the implanted neurostimulator are important limitations. The large number of patent applications linked with OSAHS treatment available in recent years points out the still increasing demand for reliable and effective therapies for this disease.

\section{Expert opinion}


CPAP is considered the most effective treatment for OSAHS and it is currently the standard of care. Despite being reliable and efficient, user's discomfort limits patient's adherence to the treatment. CPAP devices have significantly evolved since this therapy was firstly described as a non-invasive alternative to tracheotomy. Nevertheless, there is still room for improvement as evidenced by the large number of patents granted in the last few years. The reviewed CPAPrelated inventions can be grouped on (i) techniques for computing the minimal pressure that fits the patient's needs and (ii) apparatus for minimizing breathing gas leakage. The former mainly depend on signal processing techniques for the segmentation of respiratory phases (inspiration and expiration) and the detection of obstructive events, in order to gradually increase or decrease the delivered pressure. However, few details are provided concerning the performance of these techniques. The latter group of patents mainly depends on manufacturability and reproducibility of the proposed devices. Some of the major companies operating in the sleep apnea therapy market (ResMed Inc., Philips Respironics, Fisher \& Paykel or Air Liquide) are assignees of some of these patents. However, extensive research to obtain solid evidences on the usefulness, benefits and differences with similar alternatives is needed for actual successful commercialization. On the other hand, electrical stimulation of the hypoglossal nerve currently focuses the attention of the researcher and medical community. In this regard, several patents have been granted during the last years describing surgical implantation procedures, as well as electrode and electrical stimulation characteristics. Furthermore, the FDA recently approved the commercialization of the Inspire II, an implantable device based on electrical stimulation of the hypoglossal nerve for the treatment of moderate to severe OSAHS patients who cannot tolerate conventional CPAP therapy. Safety and effectiveness of this commercial device have been assessed by means of significant clinical trials, which have led to several granted patents, research papers, and finally the FDA approval. In addition, it is important to highlight the novelty of the Nyxoah's technology. Although the goal is essentially the same, i.e. electrical 
stimulation of nerves, the implant is significantly smaller than its competitors, electrodes do not require contact with the nerve to deliver electrical stimulation, and the power source is an external disposable battery patch, which simplifies surgery and maximizes the time until replacement. Nevertheless, extensive assessment by means of large clinical tests is still needed to confirm the safety and effectiveness of the device prior to commercialization. Despite the role of the upper airway dilator muscles in maintaining the patency of the airway is well known, some important issues remained regarding electrical neurostimulation for effective and continued treatment of OSAHS. Accurate stimulation of suitable nerves and muscles and fatigue prevention focused recent research. The reviewed patents linked with electrical stimulation can be divided into (i) continuous stimulation $v s$. event triggered and (ii) coarse $v s$. selective stimulation. In the first group, detection of obstructive events from respiratory-derived signals is essential for triggering electrical stimulation just when needed in order to manage fatigue. In the second group, feasible and reliable surgical techniques for the accurate attachment of the implantable electrode to the nerve are essential. Despite its potential benefits for some OSAHS patients who refuse CPAP, further research is still needed to make hypoglossal nerve stimulation a feasible alternative therapy to oral appliances and upper airway surgical procedures. Optimization of both the implantable device and the stimulation parameters will focus future inventions in order to overcome technical malfunction of the implanted neurostimulator reported in recent long-term studies. Overall, regarding both CPAP and electrical stimulation approaches, advanced signal processing techniques could significantly improve the effectiveness of these therapies. Biomedical signal processing provides accurate tools for the detection of respiratory events, such as nonlinear forecasting, statistical classifiers, neural networks, support vector machines, or ensemble learning, among others. This would allow for optimal delivery of positive pressure and electrical stimulus, improving patient's comfort and adherence to treatment. 


\section{Acknowledgements}

This research was supported by the project VA059U13 from the Consejería de Educación de la Junta de Castilla y León, the project TEC2011-22987 from Ministerio de Economía y Competitividad and FEDER, and the Proyecto Cero 2011 on Ageing from Obra Social La Caixa, Fundación General CSIC and CSIC. G. C. Gutiérrez-Tobal was in receipt of a PIRTU grant from the Consejería de Educación de la Junta de Castilla y León and the European Social Fund.

\section{Declaration of interest}

The Authors have no conflict of interest to declare.

\section{References}

1. Young T, Skatrud J, Peppard PE. Risk Factors for obstructive sleep apnea in adults. JAMA 2009;291:2013-16

2. Lopez-Jiménez F, Kuniyoshi FHS, Gami A, Somers VK. Obstructive Sleep Apnea. Chest 2008;133:793-804

3. Gharibeh T, Mehra R. Obstructive sleep apnea syndrome: natural history, diagnosis and emerging treatment options. Nature and Science of Sleep 2010;2:233-55

* This paper reviews and summarizes the main characteristics of OSAHS, including symptoms, risk factors, the standard diagnosis methodology and treatment options.

4. Redline S, Tishler PV. The genetics of sleep apnea. Sleep Medicine Reviews 2000;4:583602 
5. Kadotani H, Kadotani T, Young T, et al. Association between apolipoprotein E epsilon4 and sleepdisordered breathing in adults. JAMA 2001;285:2888-90

6. Epstein LJ, Kristo D, Strollo Jr PJ, et al. Clinical guideline for the evaluation, management and long-term care of obstructive sleep apnea in adults. Adult obstructive sleep apnea Task Force of the American Academy of Sleep Medicine. Journal of Clinical Sleep Medicine 2009;5:263-76

* This paper exhaustively analyzes the clinical guidelines and recommendations for the management of OSAHS, detailing protocols to decide the best therapy option. Main treatment approaches are thoroughly described.

7. Salisbury JI, Sun Y. Rapid screening test for sleep apnea using a nonlinear and nonstationary signal processing technique. Medical Engineering \& Physics 2007;29:33643

8. Patil SP, Schneider H, Schwartz AR, Smith PL. Adult obstructive sleep apnea. Pathophysiology and diagnosis. Chest 2007;132:325-37

9. Sassani A, Findley LJ, Kryger M, et al. Reducing Motor-Vehicle Colissions, Costs, and Fatalities by Treating Obstructive Sleep Apnea Syndrome. Sleep 2003;27:453-8

10. Lindberg E, Carter N, Gislason T, Janson C. Role of Snoring and Daytime Sleepiness in Occupational Accidents. Am J Respir Crit Care Med 2001;164:2031-35

11. Marcus CL, Brooks LJ, Ward SD, et al. Diagnosis and Management of Childhood Obstructive Sleep Apnea Syndrome. Pediatrics 2012;130:e714-55

12. Hernández L, Torrella M, Roger N, et al. Management of sleep apnea. Concordance between nonreference and reference centers. Chest 2007;132:1853-57

13. Collop NA and Epstein LJ. Entering the age of portable monitoring. Journal of Clinical Sleep Medicine 2008;4:303-4 
14. Whitelaw WA, Brant RF, Flemons WW. Clinical usefulness of home oximetry compared with polysomnography for assessment of sleep apnea. American Journal of Respiratory and Critical Care Medicine 2005;171:188-193

15. Qaseem A, Dallas P, Owens DK, et al. Diagnosis of obstructive sleep apnea in adults: A clinical practice guideline from the American College of Physicians. Annals of Internal Medicine 2014;161:210-20

16. Blau A, Minx M, Peter JG, et al. Auto bi-level pressure relief-PAP is as effective as CPAP is OSA patients - A pilot study. Sleep \& Breathing 2012;16:773-9

17. Kushida CA, Chediak A, Berry RB, et al. Positive Airway Pressure Titration Task Force of the American Academy of Sleep Medicine. Clinical guidelines for the manual titration of positive airway pressure in patients with obstructive sleep apnea. Journal of Clinical Sleep Medicine 2008;4:157-71

18. Dellacà R, Montserrat JM, Govoni L, et al. Telemetric CPAP titration at home in patients with sleep apnea-hypopnea syndrome. Sleep Medicine 2012;12:153-7

19. Weaver TE, Grunstein RR. Adherence to continuous positive airway pressure therapy. Proceedings of the American Thoracic Society 2008;5:173-8

20. McDaid C, Durée KH, Griffin SC, et al. A systematic review of continuous positive airway pressure for obstructive sleep apnea-hypopnea syndrome. Sleep Medicine Reviews 2009;13:427-36

* In this review paper, effectiveness and advantages of CPAP over secondary treatment options are analyzed. The authors highlight studies were significant differences in terms of quality of life and cardiovascular measures are found.

21. Iber C, Ancoli-Israel S, Chesson AL, Quan SF for the American Academy of Sleep Medicine. The AASM Manual for the scoring of sleep and associated events. Rules, 
terminology and technical specifications (1ST Ed). Westchester, IL: American Academy of Sleep Medicine, 2007

22. American Academy of Sleep Medicine. International classification of sleep disorders: Diagnostic and coding manual (2nd Edition). Westchester, IL: American Academy of Sleep Medicine, 2005

23. Kushida CA, Littner MR, Morgenthaler T, et al. Practice parameters for the indications for polysomnography and related procedures: an update for 2005. Sleep 2005;28:499521.

24. Flemons WW, Littner MR, Rowlet JA, et al. Home diagnosis of sleep apnea: A systematic review of the literature. Chest 2003;124:1543-79

25. Netzer N, Eliasson AH, Netzer C, Kristo DA. Overnight pulse oximetry for sleepdisordered breathing in adults. Chest 2001;120:625-33

26. Collop NA, Anderson WMcD, Boehlecke B, et al. Clinical guidelines for the use of unattended portable monitors in the diagnosis of obstructive sleep apnea in adult patients. Journal of Clinical Sleep Medicine 2007;3:737-47

27. Penzel T, McNames J, de Chazal P, et al. Systematic comparison of different algorithms for apnoea detection based on electrocardiogram recordings. Medical \& Biological Engineering \& Computing 2002;40:402-7

28. De Chazal P, Heneghan C, Sheridan E, et al. Automated processing of the single-lead electrocardiogram for the detection of obstructive sleep apnea. IEEE Transactions on Biomedical Engineering 2003;50:686-96

29. Salisbury JI, Sun Y. Rapid screening test for sleep apnea using a nonlinear and nonstationary signal processing technique. Medical Engineering \& Physics 2007;29:33643 
30. Nakano H, Tanigawa T, Furukawa T, Nishima N. Automatic detection of sleepdisordered breathing from a single-channel airflow record. Europen Respiratory Journal $2007 ; 29: 728-36$

31. Caseiro P, Fonseca-Pinto R, Andrade A. Screening of obstructive sleep apnea using Hilbert-Huang decomposition of oronasal airway pressure recordings. Medical Engineering \& Physics 2010;32:561-8

32. Zamarrón C, Romero PV, Rodríguez JR, Gude F. Oximetry spectral analysis in the diagnosis of obstructive sleep apnoea. Clinical Science 1999;97:467-73

33. Álvarez D, Hornero R, Marcos JV, del Campo F. Multivariate Analysis of Blood Oxygen Saturation Recordings in Obstructive Sleep Apnea Diagnosis. IEEE Transactions on Biomedical Engineering 2010;57:2816-24

34. Collop NA, Tracy SL, Kapur V, et al. Obstructive sleep apnea devices for out-of-center (OOC) testing: technology evaluation. Journal of Clinical Sleep Medicine 2011;7:531-48

35. Hoffstein V. Review of oral appliances for treatment sleep-disordered breathing. Sleep \& Breathing 2007;11:1-22

36. Won CHJ, Li KK, Guilleminault C. Surgical treatment of obstructive sleep apnea. Upper airway and maxillomandibular surgery. Proceedings of the American Thoracic Society 2008;5:193-9

37. Sullivan CE, Issa FG, Berthon-Jones M, Eves L. Reversal of obstructive sleep apnoea by continuous positive airway pressure applied through the nares. Lancet 1981;1:862-5

38. Weaver TE, Mancini C, Maislin G, et al. Continuous positive airway pressure treatment of sleepy patients with milder obstructive sleep apnea. Results of the CPAP Apnea Trial North American Program (CATNAP) Randomized clinical trial. American Journal of Respiratory and Critical Care Medicine 2012;186:677-83 
39. Campos-Rodríguez F, Martínez-García MA, Reyes-Núñez N, et al. Role of sleep apnea and continuous positive airway pressure therapy in the incidence of stroke or coronary heart disease in women. American Journal of Respiratory and Critical Care Medicine 2014;189:1544-50

40. Marin JM, Carrizo SJ. Mortality in obstructive sleep apnea. Sleep Medicine Clinics 2007;2:593-601

41. Somiah M, Taxin Z, Keating J, et al. Sleep quality, short-term and long-term CPAP adherence. Journal of Clinical Sleep Medicine 2012;8:489-500

42. Kezirian EJ, Boudewyns A, Eisele EW, et al. Electrical stimulation of the hypoglossal nerve in the treatment of obstructive sleep apnea. Sleep Medicine Reviews 2010;14:299305

* This paper shows the main characteristics of nerve electrical stimulation for OSAHS treatment, detailing the role of different nerve branches and motor efferents, both on animals and humans.

43. Antonescu-Turcu A, Parthasarathy S. CPAP and Bi-level PAP therapy: New and established roles. Respiratory Care 2010;55:1216-29

* In this paper, different PAP-based alternatives for OSAHS treatment are analyzed, including conventional CPAP and novel auto-adjusting techniques. Differences among treatment options in terms of effectiveness and improve of symptoms are discussed.

44. Sériès F, Marc I. Importance of sleep stage- and body position-dependence of sleep apnoea in determining benefits of auto-CPAP therapy. European Respiratory Journal $2001 ; 18: 170-5$ 
45. Ayas NT, Patel SR, Malhotra A, et al. Auto-titrating versus standard continuous positive airway pressure for the treatment of obstructive sleep apnea: results of a meta-analysis. Sleep 2004;27:249-53

46. Nilius G, Happel A, Domanski U, et al. Pressure-relief continuous positive airway pressure vs. constant continuous positive airway pressure: a comparison of efficacy and compliance. Chest 2006;130:1018-24

47. Pepin JL, Muir JF, Gentina T, et al. Pressure reduction during exhalation in sleep apnea patients treated by continuous positive airway pressure. Chest 2009;136:490-7

48. Masa JF, Jimenez A, Duran J, et al. Alternative methods of titrating continuous positive airway pressure: a large multicenter study. American Journal of Respiratory and Critical Care Medicine 2004; 170:1218-24

49. Noseda A, Kempenaers C, Kerkhofs M, et al. Constant vs. auto-continuous positive airway pressure in patients with sleep apnea hypopnea syndrome and a high variability in pressure requirement. Chest 2004;126:31-7

50. Patruno V, Aiolfi S, Costantino G, et al. Fixed and autoadjusting continuous positive airway pressure treatments are not similar in reducing cardiovascular risk factors in patients with obstructive sleep apnea. Chest 2007;131:1393-9

51. Boudewyns AN, Marklund M, Hochban W. Alternatives for OSAHS treatment: selection of patients for upper airway surgery and oral appliances. European Respiratory Reviews $2007 ; 16: 1-14$

52. Weaver TE, Calik MW, Farabi SS, et al. Innovative treatments for adults with obstructive sleep apnea. Nature and Science of Sleep 2014;6:137-47

53. Blumen MB, Vezina JP, Pigot JL, Chabolle F. Maxillomandibular advancement for obstructive sleep apnea syndrome. Operative Techniques in Otolaryngology 2012;23:606 
54. Park JG, Morgenthaler TM, Gay PC. Novel and emerging nonpositive airway pressure therapies for sleep apnea. Chest 2013;144:1946-52

55. Colrain IM, Brooks S, Black J. A pilot evaluation of a nasal expiratory resistance device for the treatment of obstructive sleep apnea. Journal of Clinical Sleep Medicine $2008 ; 4: 426-33$

56. Rosenthal L, Massie CA, Dolan DC, et al. A multicenter, prospective study of a novel nasal EPAP device in the treatment of obstructive sleep apnea: efficacy and 30-day adherence. Journal of Clinical Sleep Medicine 2009;5:532-7

57. Colrain IM, Black J, Siegel LC, et al. A multicenter evaluation of oral pressure therapy for the treatment of obstructive sleep apnea. Sleep Medicine 2013;14:830-7

58. Schwartz AR, Eisele DW, Hari A, et al. Electrical stimulation of the lingual musculature in obstructive sleep apnea. Journal of Applied Physiology 1996;81:643-52

59. Oliven A, Odeh M, Geitini L, et al. Effect of coactivation of tongue protrusor and retractor muscles on pharyngeal lumen and airflow in sleep apnea. Journal of Applied Physiology 2007; 103:1662-8

60. Mwenge GB, Rombaux P, Dury M, et al. Targeted hypoglossal neurostimulation for obstructive sleep apnoea: a 1-year pilot study. European Respiratory Journal $2013 ; 41: 360-7$

61. Strollo PJ Jr, Soose RJ, Maurer JT, et al. Upper-airway stimulation for obstructive sleep apnea. The New England Journal of Medicine 2014;370:139-49.

62. Eastwood PR, Barnes M, Walsh JH, et al. Treating obstructive sleep apnea with hypoglossal nerve stimulation. Sleep 2011;34:1479-86

63. Imthera Medical Inc. Method of stimulating a hypoglossal nerve for controlling the position of a patient's tongue. US8428725 (2013) 
* In this patent, the inventors present techniques and devices to avoid the main limitations of electrical nerve stimulation of the hypoglossal nerve: non-selective stimulation and fatigue.

64. New York University, Puritan Bennett Corporation. System for optimizing continuous positive airway pressure for treatment of obstructive sleep apnea. AU705270 (1999)

65. New York University, Puritan Bennett Corporation. System for optimizing continuous positive airway pressure for treatment of obstructive sleep apnea. EP0759791 (2002)

66. New York University, Puritan Bennett Corporation. System for optimising continuous positive airway pressure for treatment of obstructive sleep apnea. EP1172123 (2004)

67. New York University, Puritan Bennett Corporation. System for optimizing continuous positive airway pressure for treatment of obstructive sleep apnea. CA2190488 (2007)

68. New York University, Puritan Bennett Corporation. Method and apparatus for optimizing the continuous positive airway pressure for treating obstructive sleep apnea. US6299581 (2001)

69. New York University. Method and apparatus for optimizing the continuous positive airway pressure for treating obstructive sleep apnea. US6488634 (2002)

70. New York University, Puritan Bennett Corporation. Method and apparatus for optimizing the continuous positive airway pressure for treating obstructive sleep apnea. US6793629 (2004)

* In this patent, a methodology for the detection of airflow limitation is presented in order to automatically fit delivered pressure to patient's needs. Signal processing techniques (feature extraction and classification) applied to the airflow signal are described.

71. New York University. System and method for classifying patient's breathing using artificial neural network. US7276031 (2007) 
72. New York University. Method and apparatus for optimizing the continuous positive airway pressure for treating obstructive sleep apnea. US7901361 (2011)

73. Breas Medical AB. Auto CPAP. US6889691 (2005)

74. The Board of Trustees of the University of Illinois. Detection and prediction of physiological events in people with sleep disordered breathing using a LAMSTAR neural network. US8775340 (2014)

75. Breas Medical AB. Multilevel ventilator. EP1750581 (2014)

76. Ayappa I, Norman RG, Whiting D, et al. Irregular respiration as a marker of wakefulness during titration of CPAP. Sleep 2009;32:99-104

77. Dungan GC, Marshall NS, Hoyos CM, et al. A randomized crossover trial of the effect of a novel method of pressure control (SensAwake) in automatic continuous positive airway pressure therapy to treat sleep disordered breathing. Journal of Clinical Sleep Medicine 2011;7:261-7

78. New York University. Positive airway pressure system and method for treatment of sleeping disorder in patient. US6988994 (2006)

79. Fisher \& Paykel Healthcare Limited. System, apparatus and method for supplying gases. US2014/0000610A1 (2014)

80. Fisher \& Paykel Healthcare Limited. Apparatus and method for providing gases to a user. US2013/0133656A1 (2013)

81. RIC Investments Inc. Apparatus for providing positive airway pressure to a patient. AU2003295925 (2006)

82. RIC Investments Inc. Apparatus for providing positive airway pressure to a patient. CA2507254 (2011)

83. Respironics Inc. Method and apparatus for providing positive airway pressure to a patient. EP1061981 (2010) 
84. RIC Investments Inc. Apparatus for providing positive airway pressure to a patient. EP1565224 (2012)

85. RIC Investments Inc. Method and apparatus for providing positive airway pressure to a patient. US6932084 (2005)

86. RIC Investments LLC. Method and apparatus for providing positive airway pressure to a patient. US7296573 (2007)

87. RIC Investments LLC. Method and apparatus for providing positive airway pressure to a patient. US7810496 (2010)

* This patent shows a methodology for computing the delivered optimal pressure during inspiration (IPAP) and expiration (EPAP) phases in a BPAP device.

88. Childers WD, Childers RO. Parameter optimization in sleep apnea treatment apparatus. US7469698 (2008)

89. Childers WD. Parameter optimization in sleep apnea treatment apparatus. US7926486 (2011)

90. Curative (Beijing) Medical Technology Co. Ltd. Method and apparatus for providing positive airway pressure to a patient. US8256417 (2012)

91. Curative (Beijing) Medical Technology Co. Ltd. Apparatus for providing positive airway pressure to a patient. US8684001 (2014)

92. Ventific Holdings Pty Ltd. Automatic positive airway pressure therapy through the nose or mouth for treatment of sleep apnea and other respiratory disorders. US8316847 (2012)

93. Fietze I, Penzel T, Alonderis A, et al. Management of obstructive sleep apnea in Europe. Sleep Medicine 2011;12:190-7

94. Grady D. CPAP enclosure for the treatment of sleep apnea. US7520277 (2009)

95. ResMed Limited. Flow diverter for controlling the pressure and flow rate in a CPAP device. US6745770 (2004) 
96. ResMed Limited. Flow diverter for controlling the pressure and flow rate in a CPAP device. US6895964 (2005)

97. ResMed Limited. Flow diverter for controlling the pressure and flow rate in a CPAP device. AU2002324018 (2006)

98. ResMed Limited. Flow diverter for controlling the pressure and flow rate in CPAP device. US7036506 (2006)

99. ResMed Limited. Flow diverter for controlling the pressure and flow rate in CPAP device. US7527055 (2009)

100. ResMed Limited. Flow diverter for controlling the pressure and flow rate in CPAP device. US7694679 (2010)

101. Air Liquide Medical Systems. Improved membrane cushion for facial mask for treating sleep disorders. EP2478925 (2014)

102. ResMed Limited. Cushion for a respiratory mask assembly. US7523754 (2009)

103. Respironics Inc. Nasal mask and system using same. US6959710 (2005)

104. White DP. Pathogenesis of obstructive and central sleep apnea. American Journal of Respiraory and Crittical Care Medicine 2005;172:1363-70

105. Imthera Medical Inc. RFID-based apparatus, system, and method for therapeutic treatment of obstructive sleep apnea. US7725195 (2010)

106. Imthera Medical Inc. Apparatus, system, and method for therapeutic treatment of obstructive sleep apnea. US7937159 (2011)

107. Imthera Medical Inc. Method of stimulating a hypoglossal nerve for controlling the position of a patient's tongue. AU2009302591 (2014)

108. Imthera Medical Inc. Method of stimulating a hypoglossal nerve for controlling the position of a patients tongue. US8751005 (2014) 
109. Huntington Medical Research Institutes. Apparatus and method for treating obstructive sleep apnea. US8249723 (2012)

110. Huntington Medical Research Institutes. Apparatus and method for treating obstructive sleep apnea. US8359108 (2013)

111. Huntington Medical Research Institutes. Apparatus and method for treating obstructive sleep apnea. US8774943 (2014)

112. Apnex Medical Inc. Obstructive sleep apnea treatment devices, systems and methods. US7809442 (2010)

113. Apnex Medical Inc. Obstructive sleep apnea treatment devices, systems and methods. US8311645 (2012)

114. Apnex Medical Inc. Obstructive sleep apnea treatment devices, systems and methods. US8428727 (2013)

* In this patent, a detailed description of surgical procedures, implanted electrode shapes and materials, and methods for triggering stimuli are described, in order to perform non-continuous and selective electrical stimulation of the hypoglossal nerve.

115. Cyberonics Inc. Obstructive sleep apnea treatment devices, systems and methods. US8639354 (2014)

116. Cyberonics Inc. Obstructive sleep apnea treatment devices, systems and methods. US8718783 (2014)

117. Apnex Medical Inc. Screening devices and methods for obstructive sleep apnea therapy. US8386046 (2013)

118. Inspire Medical Systems Inc. System for treating sleep disordered breathing. US8938299 (2015) 
119. Inspire Medical Systems Inc. System and method for patient selection in treating sleep disordered breathing. US8983572 (2015)

* The inventors describe a screening methodology to select those patients more likely to benefit from electrical nerve stimulation therapy. The technique is based on the characterization of the upper airway obstruction by means of medical imaging, respiratory-related recordings, and the patient health history.

120. Inspire Medical Systems Inc. Nerve cuff. US8934992 (2015)

121. Inspire Medical Systems Inc. Transvenous method of treating sleep apnea. US2011/0202119A1 (2011)

122. Inspire Medical Systems Inc. Percutaneous access for systems and methods of treating sleep apnea. US2012/0089153A1 (2012)

123. Inspire Medical Systems Inc. Method and system for identifying a location for nerve stimulation. US2013/0204097A1 (2013)

124. Inspire Medical Systems Inc. Method and apparatus for sensing respiratory pressure in an implantable stimulation system. US2011/0152706A1 (2011)

125. Nyxoah. Systems and methods for determining sleep disorder based on positioning of the tongue. US8577472 (2013)

126. Nyxoah. Apparatus and method for detecting a sleep disordered breathing precursor. US8574164 (2013)

127. Nyxoah. System and method for nerve modulation using noncontacting electrodes. US8577466 (2013)

* In this patent, the nerve modulation technique based on non-contacting fieldgenerating electrodes is described. An electric field provides energy to the nerve and creates an adequate voltage change to regulate nerve activity. 
128. Nyxoah. Device and method for modulating nerves using parallel electric fields. US8588941 (2013)

129. Nyxoah. Devices and methods for low current neural modulation. US8700183 (2014)

130. Nyxoah. Apparatus and method to control an implant. US8718776 (2014)

131. Nyxoah. Apparatus and method for extending implant life using a dual power scheme. US8577468 (2013)

132. Rodenstein D, Rombaux P, Lengele B, et al. Residual effect of THN hypoglossal stimulation in obstructive sleep apnea: a disease-modifying therapy. American Journal of Respiratory and Critical Care Medicine 2013;187:1276-8

133. Woodson BT, Gillespie MB, Soose RJ, et al. Randomized controlled withdrawal study of upper airway stimulation on OSA: short- and long-term effect. Otolaryngoly - Head and Neck Surgery 2014;151:880-7

134. Van de Heyning PH, Badr MS, Baskin JZ, et al. Implanted upper airway stimulation device for obstructive sleep apnea. Laryngoscope 2012;122:1626-33.

135. Vanderveken OM, Maurer JT, Hohenhorst W, et al. Evaluation of drug-induced sleep endoscopy as a patient selection tool for implanted upper airway stimulation for obstructive sleep apnea. J Clin Sleep Med 2013;9:433-8. 


\section{Tables}

\begin{tabular}{|c|c|c|c|}
\hline Therapy approach & Modalities & Advantages & Disadvantages \\
\hline $\begin{array}{l}\text { Positive airway } \\
\text { pressure devices }\end{array}$ & $\begin{array}{l}\text { - Continuous (CPAP) } \\
\text { - Bi-level (BPAP) } \\
\text { - Self-adjusting (Auto-PAP) }\end{array}$ & $\begin{array}{l}\text { - Non-invasive } \\
\text { - Reversible } \\
\text { - Highly effective }\end{array}$ & $\begin{array}{l}\text { - Leakage } \\
\text { - Patient's discomfort } \\
\text { (dryness, irritation) } \\
\text { - Low compliance }\end{array}$ \\
\hline Oral appliances & $\begin{array}{l}\text { - Tongue retaining } \\
\text { - Mandibular repositioning }\end{array}$ & $\begin{array}{l}\text { - Removable } \\
\text { - Custom-made }\end{array}$ & $\begin{array}{l}\text { - Pain } \\
\text { - Irritation } \\
\text { - Excessive salivation }\end{array}$ \\
\hline Surgical & $\begin{array}{l}\text { - Hyoid suspension } \\
\text { - Uvulopalatopharyngoplasty } \\
\text { - Maxillomandibular advancement }\end{array}$ & $\begin{array}{l}\text { - Effective in } \\
\text { selected patients }\end{array}$ & $\begin{array}{l}\text { - Non-reversible } \\
\text { - Highly invasive }\end{array}$ \\
\hline $\begin{array}{l}\text { Behavioral and } \\
\text { pharmacological }\end{array}$ & $\begin{array}{l}\text { - Life style changes (weight loss, } \\
\text { sleep position change) } \\
\text { - Supplemental oxygen, modafinil }\end{array}$ & $\begin{array}{l}\text { - Non-invasive } \\
\text { - Reversible }\end{array}$ & $\begin{array}{l}\text { - Adjunctive therapies to } \\
\text { additional primary } \\
\text { treatment }\end{array}$ \\
\hline $\begin{array}{l}\text { Electrical } \\
\text { stimulation }\end{array}$ & $\begin{array}{l}\text { - Event triggered } \\
\text { - Continuous stimulation }\end{array}$ & $\begin{array}{l}\text { - Removable } \\
\text { implanted device } \\
\text { - No compliance } \\
\text { issues linked with } \\
\text { uncomfortable } \\
\text { appliances }\end{array}$ & $\begin{array}{l}\text { - Needs surgery } \\
\text { - Muscle and nerve } \\
\text { fatigue } \\
\text { - Induced arousals }\end{array}$ \\
\hline
\end{tabular}

Table 1. Overview of the main therapies currently available for OSAHS treatment, advantages and limitations. 


\begin{tabular}{|c|c|c|c|}
\hline $\begin{array}{l}\text { Therapy } \\
\text { approach }\end{array}$ & Title (number) & Main features of patented invention & Ref. \\
\hline $\begin{array}{l}\text { Positive airway } \\
\text { pressure } \\
\text { delivery (auto- } \\
\text { adjusting) }\end{array}$ & $\begin{array}{l}\text { System for optimizing } \\
\text { continuous positive airway } \\
\text { pressure for treatment of } \\
\text { obstructive sleep apnea } \\
\text { (AU705270) } \text { (CA2190488) } \\
\text { (EP0759791) (EP1172123) } \\
\text { Method and apparatus for } \\
\text { optimizing the continuous } \\
\text { positive airway pressure for } \\
\text { treating obstructive sleep apnea } \\
\text { (US6299581) (US6488634) } \\
\text { (US6793629) } \\
\text { (US7901361) } \\
\text { System and method for } \\
\text { classifying patient's breathing } \\
\text { using artificial neural network } \\
\text { (US7276031) }\end{array}$ & $\begin{array}{l}\text { Automated detection of airflow limitation } \\
\text { based on shaped-based parameters derived } \\
\text { from airflow monitoring using signal } \\
\text { processing methods (logistic regression } \\
\text { and decision tree). The invention can be } \\
\text { used either for treatment or for diagnostic } \\
\text { purposes. } \\
\text { neural network. } \\
\text { Automated classification of airflow } \\
\text { limitation using a pre-trained artificial } \\
\text { nen }\end{array}$ & $\begin{array}{l}{[64-67]} \\
{[68-70,72]}\end{array}$ \\
\hline $\begin{array}{l}\text { Positive airway } \\
\text { pressure } \\
\text { delivery (auto- } \\
\text { adjusting) }\end{array}$ & Auto CPAP (US6889691) & $\begin{array}{l}\text { The system detects patterns characteristic } \\
\text { of sleep disordered breathing to control the } \\
\text { pressure of gas delivered to a patient. } \\
\text { Airflow is parameterized by the cesptrum } \\
\text { coefficients and the energy content, which } \\
\text { are fed to an artificial neural network to } \\
\text { detect airflow limitation. }\end{array}$ & {$[73]$} \\
\hline $\begin{array}{l}\text { Positive airway } \\
\text { pressure } \\
\text { delivery (auto- } \\
\text { adjusting) }\end{array}$ & $\begin{array}{l}\text { Detection and prediction of } \\
\text { physiological events in people } \\
\text { with sleep disordered breathing }\end{array}$ & $\begin{array}{l}\text { The invention applies advanced signal } \\
\text { processing techniques (Wavelet transform } \\
\text { and LAMSTAR neural networks) to detect } \\
\text { and predict respiratory events from }\end{array}$ & {$[74]$} \\
\hline
\end{tabular}




\begin{tabular}{|c|c|c|c|}
\hline & $\begin{array}{l}\text { using a LAMSTAR neural } \\
\text { network (US8775340) }\end{array}$ & $\begin{array}{l}\text { physiological recordings, in order to } \\
\text { modulate the pressure level according to } \\
\text { the patient's needs. }\end{array}$ & \\
\hline $\begin{array}{l}\text { Positive airway } \\
\text { pressure } \\
\text { delivery (auto- } \\
\text { adjusting) }\end{array}$ & $\begin{array}{l}\text { Multilevel ventilator } \\
(\mathrm{EP} 1750581)\end{array}$ & $\begin{array}{l}\text { The proposed system performs pattern } \\
\text { recognition by means of a plurality of } \\
\text { artificial neural networks to control the } \\
\text { breathing support. }\end{array}$ & {$[75]$} \\
\hline $\begin{array}{l}\text { Positive airway } \\
\text { pressure } \\
\text { delivery (auto- } \\
\text { adjusting) }\end{array}$ & $\begin{array}{l}\text { Positive airway pressure system } \\
\text { and method for treatment of } \\
\text { sleeping disorder in patient } \\
\text { (US6988994) }\end{array}$ & $\begin{array}{l}\text { Signal processing techniques are applied } \\
\text { to analyze breathing patterns in order to } \\
\text { detect wakefulness, sleep, normal } \\
\text { breathing and disturbance breathing. As a } \\
\text { result, the airflow pressure delivered to the } \\
\text { patient is varied. }\end{array}$ & {$[78]$} \\
\hline $\begin{array}{l}\text { Positive airway } \\
\text { pressure } \\
\text { delivery (auto- } \\
\text { adjusting) }\end{array}$ & $\begin{array}{l}\text { System, apparatus and method } \\
\text { for supplying gases } \\
\text { (US2014/0000610A1) }\end{array}$ & $\begin{array}{l}\text { The system delivers a therapeutic pressure } \\
\text { level when the patient is asleep and a lower } \\
\text { pressure when the user is awake. }\end{array}$ & [79] \\
\hline $\begin{array}{l}\text { Positive airway } \\
\text { pressure } \\
\text { delivery (auto- } \\
\text { adjusting) }\end{array}$ & $\begin{array}{l}\text { Apparatus and method for } \\
\text { providing gases to a user } \\
\text { (US2013/0133656A1) }\end{array}$ & $\begin{array}{l}\text { The system analyzes breathing patterns } \\
\text { and user interactions with the PAP device } \\
\text { to detect sleep onset and wakefulness. }\end{array}$ & {$[80]$} \\
\hline $\begin{array}{l}\text { Positive airway } \\
\text { pressure } \\
\text { delivery (auto- } \\
\text { adjusting) }\end{array}$ & $\begin{array}{l}\text { Apparatus for providing positive } \\
\text { airway pressure to a patient } \\
\text { (AU2003295925) (CA2507254) } \\
\text { (EP1565224) } \\
\text { Method and apparatus for } \\
\text { providing positive airway } \\
\text { pressure to a patient } \\
\text { (US6932084) (US7296573) } \\
\text { (US7810496) (EP1061981) }\end{array}$ & $\begin{array}{l}\text { The system computes the optimal } \\
\text { minimum pressure during inspiration and } \\
\text { expiration depending on the estimated } \\
\text { patient's flow rate. The invention is able to } \\
\text { detect obstructive apneas, hypopneas and } \\
\text { central apneas. }\end{array}$ & $\begin{array}{l}{[81,82,84]} \\
{[83,85-} \\
87]\end{array}$ \\
\hline
\end{tabular}




\begin{tabular}{|c|c|c|c|}
\hline $\begin{array}{l}\text { Positive airway } \\
\text { pressure } \\
\text { delivery (auto- } \\
\text { adjusting) }\end{array}$ & $\begin{array}{l}\text { Parameter optimization in sleep } \\
\text { apnea treatment apparatus } \\
\text { (US7469698) (US7926486) }\end{array}$ & $\begin{array}{l}\text { The invention describes a methodology } \\
\text { and a system for managing therapy at } \\
\text { home. Prescribed or auto-adjusting custom } \\
\text { pressure parameters can be set in the } \\
\text { system to optimize the delivered pressure. }\end{array}$ & {$[88,89]$} \\
\hline $\begin{array}{l}\text { Positive airway } \\
\text { pressure } \\
\text { delivery (bi- } \\
\text { level) }\end{array}$ & $\begin{array}{l}\text { Method and apparatus for } \\
\text { providing positive airway } \\
\text { pressure to a patient } \\
\text { (US8256417) } \\
\text { Apparatus for providing positive } \\
\text { airway pressure to a patient } \\
\text { (US8684001) }\end{array}$ & $\begin{array}{l}\text { Improvement of synchrony between } \\
\text { patient's inspiration and expiration stages } \\
\text { and bi-level delivered pressure. } \\
\text { Correlation between monitored patient's } \\
\text { airflow signal and delivered pressure } \\
\text { signal is used. }\end{array}$ & [90] \\
\hline $\begin{array}{l}\text { Positive airway } \\
\text { pressure } \\
\text { delivery (bi- } \\
\text { level) }\end{array}$ & $\begin{array}{l}\text { Automatic positive airway } \\
\text { pressure therapy through the nose } \\
\text { or mouth for treatment of sleep } \\
\text { apnea and other respiratory } \\
\text { disorders (US8316847) }\end{array}$ & $\begin{array}{l}\text { Automated optimization of IPAP and } \\
\text { EPAP delivered pressures based on } \\
\text { respiratory-related parameters. }\end{array}$ & [92] \\
\hline $\begin{array}{l}\text { Positive airway } \\
\text { pressure } \\
\text { delivery } \\
\text { (complete } \\
\text { enclosure) }\end{array}$ & $\begin{array}{l}\text { CPAP enclosure for the treatment } \\
\text { of sleep apnea (US7520277) }\end{array}$ & $\begin{array}{l}\text { A complete enclosure is described to } \\
\text { provide PAP therapy without the need for } \\
\text { a fitted mask. }\end{array}$ & [94] \\
\hline $\begin{array}{l}\text { Positive airway } \\
\text { pressure } \\
\text { delivery (flow } \\
\text { diverter) }\end{array}$ & $\begin{array}{l}\text { Flow diverter for controlling the } \\
\text { pressure and flow rate in a CPAP } \\
\text { device } \\
\text { (US6745770) } \\
\text { (US6895964) (AU2002324018) } \\
\text { (US7036506) (US7527055) } \\
\text { (US7694679) }\end{array}$ & $\begin{array}{l}\text { Delivered breathing gas pressure is } \\
\text { controlled by means of a flow diverter } \\
\text { rotatable vane inserted between the patient } \\
\text { mask and the flow generator. }\end{array}$ & [95-100] \\
\hline
\end{tabular}




\begin{tabular}{|c|c|c|c|}
\hline $\begin{array}{l}\text { Positive airway } \\
\text { pressure } \\
\text { delivery (facial } \\
\text { mask) }\end{array}$ & $\begin{array}{l}\text { Improved membrane cushion for } \\
\text { facial mask for treating sleep } \\
\text { disorders (EP2478925) }\end{array}$ & $\begin{array}{l}\text { The invention describes a cushion for a } \\
\text { respiratory mask able to deliver efficient } \\
\text { gas tightness whatever the patient's } \\
\text { physiognomy. }\end{array}$ & [101] \\
\hline $\begin{array}{l}\text { Positive airway } \\
\text { pressure } \\
\text { delivery (facial } \\
\text { mask) }\end{array}$ & $\begin{array}{l}\text { Cushion for a respiratory mask } \\
\text { assembly (US7523754) }\end{array}$ & $\begin{array}{l}\text { The invention describes a cushion for } \\
\text { controlling the distribution of contact } \\
\text { force of a respiratory mask around the } \\
\text { patient's face. }\end{array}$ & [102] \\
\hline $\begin{array}{l}\text { Positive airway } \\
\text { pressure } \\
\text { delivery (facial } \\
\text { mask) }\end{array}$ & $\begin{array}{l}\text { Nasal mask and system using } \\
\text { same (US6959710) }\end{array}$ & $\begin{array}{l}\text { The invention describes different } \\
\text { structures and areas of a cushion designed } \\
\text { to control the contact area of the mask- } \\
\text { patient interface. }\end{array}$ & [103] \\
\hline $\begin{array}{l}\text { Electrical nerve } \\
\text { stimulation } \\
\text { (continuous) }\end{array}$ & $\begin{array}{l}\text { RFID-based apparatus, system, } \\
\text { and method for therapeutic } \\
\text { treatment of obstructive sleep } \\
\text { apnea (US7725195) } \\
\text { Apparatus, system, and method } \\
\text { for therapeutic treatment of } \\
\text { obstructive sleep apnea } \\
\text { (US7937159) }\end{array}$ & $\begin{array}{l}\text { RFID-enabled microelectronic } \\
\text { neurostimulator system. The system } \\
\text { performs selective stimulation of } \\
\text { hypoglossus and styloglosus by means of } \\
\text { multiple nerve stimulating points. }\end{array}$ & [106] \\
\hline $\begin{array}{l}\text { Electrical nerve } \\
\text { stimulation } \\
\text { (continuous) }\end{array}$ & $\begin{array}{l}\text { Method of stimulating a } \\
\text { hypoglossal nerve for controlling } \\
\text { the position of a patient's tongue } \\
\text { (AU2009302591) (US8428725) } \\
\text { (US8751005) }\end{array}$ & $\begin{array}{l}\text { The invention describes a method for } \\
\text { selective electrical stimulation of the } \\
\text { motor efferents of the hypoglossal nerve. } \\
\text { Continuous but controlled stimuli are } \\
\text { delivered to minimize fatigue }\end{array}$ & $\begin{array}{l}{[63,107,} \\
108]\end{array}$ \\
\hline $\begin{array}{l}\text { Electrical nerve } \\
\text { stimulation } \\
\text { (event } \\
\text { triggered) }\end{array}$ & $\begin{array}{l}\text { Apparatus and method for } \\
\text { treating obstructive sleep apnea } \\
\text { (US8249723) (US8359108) } \\
\text { (US8774943) }\end{array}$ & $\begin{array}{l}\text { The invention monitors the position of the } \\
\text { tongue to detect obstructive events (the } \\
\text { tongue moves onto the airway causing the } \\
\text { apnea). Then, electrical stimuli are } \\
\text { delivered to the branches of the motor }\end{array}$ & [109-111] \\
\hline
\end{tabular}




\begin{tabular}{|c|c|c|c|}
\hline & & $\begin{array}{l}\text { nerves of the tongue to recover airway } \\
\text { patency. }\end{array}$ & \\
\hline $\begin{array}{l}\text { Electrical nerve } \\
\text { stimulation } \\
\text { (event } \\
\text { triggered) }\end{array}$ & $\begin{array}{l}\text { Obstructive sleep apnea } \\
\text { treatment devices, systems and } \\
\text { methods } \quad \text { (US7809442) } \\
\text { (US8311645) (US8428727) } \\
\text { (US8639354) (US8718783) }\end{array}$ & $\begin{array}{l}\text { The proposed system detects respiratory } \\
\text { events by means of external and/or } \\
\text { implanted sensors to trigger electrical } \\
\text { stimuli. Different signal processing stages } \\
\text { are applied to compute respiratory-derived } \\
\text { control parameters. }\end{array}$ & [112-116] \\
\hline $\begin{array}{l}\text { Electrical nerve } \\
\text { stimulation } \\
\text { (pre-surgery } \\
\text { test) }\end{array}$ & $\begin{array}{l}\text { Screening devices and methods } \\
\text { for obstructive sleep apnea } \\
\text { therapy (US8386046) }\end{array}$ & $\begin{array}{l}\text { The inventors describe a methodology for } \\
\text { assessing the likelihood of therapeutic } \\
\text { success of electrical stimulation before the } \\
\text { surgery. }\end{array}$ & [117] \\
\hline $\begin{array}{l}\text { Electrical nerve } \\
\text { stimulation } \\
\text { (event } \\
\text { triggered) }\end{array}$ & $\begin{array}{l}\text { System for treating sleep } \\
\text { disordered } \\
\text { (US8938299) } \\
\text { System and method for patient } \\
\text { selection in treating sleep } \\
\text { disordered } \\
\text { (US8983572) breathing } \\
\text { Nerve cuff (US8934992) }\end{array}$ & $\begin{array}{l}\text { Recent granted patents by Inspire Medical } \\
\text { Systems Inc.: } \\
\text { (i) Automatic therapy manager based on } \\
\text { respiration and body position (activity and } \\
\text { posture) monitoring. } \\
\text { (ii) Methodology for patient screening } \\
\text { based on medical images and biosignals } \\
\text { and the patient's health history. } \\
\text { (iii) Stimulating electrode characteristics. }\end{array}$ & [119] \\
\hline $\begin{array}{l}\text { Electrical nerve } \\
\text { stimulation } \\
\text { (event } \\
\text { triggered) }\end{array}$ & $\begin{array}{l}\text { Transvenous method of treating } \\
\text { sleep } \\
\text { (US2011/0202119A1) } \\
\text { Percutaneous access for systems } \\
\text { and methods of treating sleep } \\
\text { apnea (US2012/0089153A1) } \\
\text { Method and system for } \\
\text { identifying a location for nerve }\end{array}$ & $\begin{array}{l}\text { Recent patent applications by Inspire } \\
\text { Medical Systems Inc.: } \\
\text { (i) Minimally invasive techniques for } \\
\text { insertion of sensing and stimulation leads. } \\
\text { (ii) Technique for suitable electrode } \\
\text { positioning. } \\
\text { (iii) Methodology for respiratory effort } \\
\text { monitoring to control the therapy level. }\end{array}$ & {$[121,122]$} \\
\hline
\end{tabular}




\begin{tabular}{|c|c|c|c|}
\hline & $\begin{array}{l}\text { stimulation } \\
\text { (US2013/0204097A1) } \\
\text { Method and apparatus for sensing } \\
\text { respiratory pressure in an } \\
\text { implantable stimulation system } \\
\text { (US2011/0152706A1) }\end{array}$ & & \\
\hline $\begin{array}{l}\text { Electrical nerve } \\
\text { stimulation } \\
\text { (event } \\
\text { triggered) }\end{array}$ & 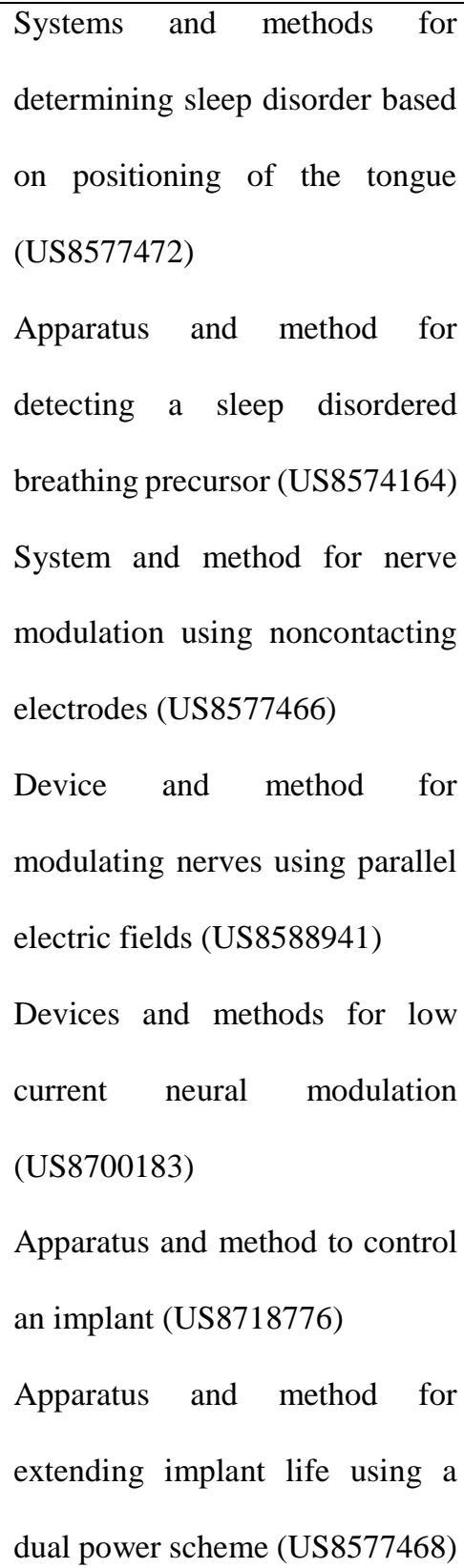 & $\begin{array}{l}\text { Nyxoah's neuromodulator technology: } \\
\text { (i) Methodology to detect tongue } \\
\text { movements based on the degree of } \\
\text { coupling between adjacent antennas. } \\
\text { (ii) Description of the nerve modulation } \\
\text { technique based on non-contacting field- } \\
\text { generating electrodes. } \\
\text { (iii) Methodology for power supplying to } \\
\text { an implant from the external unit by means } \\
\text { of electromagnetic fields. }\end{array}$ & $\begin{array}{l}{[125,126]} \\
{[127-129]} \\
{[130,131]}\end{array}$ \\
\hline
\end{tabular}

Table 2. Reviewed granted patents $(2005$ - 2014) related to PAP and electrical nerve stimulation therapies for OSAHS treatment. 


\section{List of abbreviations}

AASM: American Academy of Sleep Medicine

AF: airflow

AHI: apnea-hypopnea index

Auto-PAP: auto-adjusting continuous positive airway pressure

BPAP: bi-level positive airway pressure

CCC: complete concentric collapse

CPAP: continuous positive airway pressure

$\mathrm{CV}$ : coefficient of variation

DISE: drug-induced sleep endoscopy

ECG: electrocardiogram

EEG: electroencephalogram

EMG: electromyogram

EOG: electrooculogram

EPAP: expiratory positive airway pressure

FDA: U.S. Food and Drug Administration

IPAP: inspiratory positive airway pressure

OSAHS: obstructive sleep apnea-hypopnea syndrome

PAP: positive airway pressure

PP: peak-to-peak

PPAP: proportional positive airway pressure

PPmax: maximum PP amplitude

PPmin: minimum PP amplitude

PSG: polysomnography

RFID: radio frequency identification 
$\mathrm{SpO}_{2}$ : blood oxygen saturation

UAS: upper airway stimulation 